\title{
The metabolic significance of octulose phosphates in the photosynthetic carbon reduction cycle in spinach
}

\author{
John F. Williams · John K. MacLeod
}

Received: 19 July 2006/ Accepted: 17 October 2006/Published online: 8 December 2006

(C) Springer Science+Business Media B.V. 2006

\begin{abstract}
C}$-Labelled octulose phosphates were formed during photosynthetic ${ }^{14} \mathrm{CO}_{2}$ fixation and were measured in spinach leaves and chloroplasts. Because mono- and bisphosphates of D-glycero-D-idooctulose are the active 8-carbon ketosugar intermediates of the L-type pentose pathway, it was proposed that they may also be reactants in a modified CalvinBenson-Bassham pathway reaction scheme. This investigation therefore initially focussed only on the ido-epimer of the octulose phosphates even though ${ }^{14}$ C-labelled D-glycero-D-altro-octulose mono- and bisphosphates were also identified in chloroplasts and leaves. ${ }^{14} \mathrm{CO}_{2}$ predominantly labelled positions 5 and 6 of D-glycero-D-ido-octulose $1,8-\mathrm{P}_{2}$ consistent with labelling predictions of the modified scheme. The kinetics of ${ }^{14} \mathrm{CO}_{2}$ incorporation into ido-octulose was similar to its incorporation into some traditional intermediates of the path of carbon, while subsequent exposure to ${ }^{12} \mathrm{CO}_{2}$ rapidly displaced the ${ }^{14} \mathrm{C}$ isotope label from octulose with the same kinetics of label loss as some of the confirmed Calvin pathway intermediates. This is consistent with octulose phosphates having the role of cyclic intermediates rather than synthesized storage products. (Storage products don't rapidly exchange isotopically labelled carbons with unlabelled $\mathrm{CO}_{2}$.)
\end{abstract}

J. F. Williams $(\bowtie) \cdot$ J. K. MacLeod

Research School of Chemistry, Australian National

University, Canberra, A.C.T. 0200, Australia

e-mail: jfw@rsc.anu.edu.au

J. F. Williams

Division of Biochemistry and Molecular Biology, Australian

National University, Canberra, A.C.T. 0200, Australia
A spinach chloroplast extract, designated stromal enzyme preparation (SEP), catalysed and was used to measure rates of $\mathrm{CO}_{2}$ assimilation with Calvin cycle intermediates and octulose and arabinose phosphates. Only pentose (but not arabinose) phosphates and sedoheptulose 7-phosphate supported $\mathrm{CO}_{2}$ fixation at rates in excess of $120 \mu \mathrm{mol} \mathrm{h}^{-1} \mathrm{mg}^{-1} \mathrm{Chl}$. Rates for octulose, sedoheptulose and fructose bisphosphates, octulose, hexose and triose monophosphates were all notably less than the above rate and arabinose 5-phosphate was inactive. Altro-octulose phosphates were more active than phosphate esters of the ido-epimer. The modified scheme proposed a specific phosphotransferase and SEP unequivocally catalysed reversible phosphate transfer between sedoheptulose bisphosphate and D-glycero-Dido-octulose 8-phosphate. It was also initially hypothesized that arabinose 5-phosphate, an L-Type pentose pathway reactant, may have a role in a modified Calvin pathway. Arabinose 5-phosphate is present in spinach chloroplasts and leaves. Radiochromatography showed that ${ }^{14} \mathrm{C}$-arabinose 5-phosphate with SEP, but only in the presence of an excess of unlabelled ribose 5-phosphate, lightly labelled ribulose 5-phosphate and more heavily labelled hexose and sedoheptulose mono- and bisphosphates. However, failure to demonstrate any $\mathrm{CO}_{2}$ fixation by arabinose 5-phosphate as sole substrate suggested that the above labelling may have no metabolic significance. Despite this arabinose and ribose 5-phosphates are shown to exhibit active roles as enzyme co-factors in transaldolase and aldolase exchange reactions that catalyse the epimeric interconversions of the phosphate esters of ido- and altro-octulose. Arabinose 5phosphate is presented as playing this role in a New Reaction Scheme for the path of carbon, where it is concluded that slow reacting ido-octulose 1,8 bisphos- 
phate has no role. The more reactive altro-octulose phosphates, which are independent of the need for phosphotransferase processing, are presented as intermediates in the new scheme. Moreover, using the estimates of phosphotransferase activity with altrooctulose monophosphate as substrate allowed calculation of the contributions of the new scheme, that ranged from $11 \%$ based on the intact chloroplast carboxylation rate to $80 \%$ using the carboxylation rate required for the support of octulose phosphate synthesis and its role in the phosphotransferase reaction.

Keywords Arabinose 5-phosphate - Calvin Cycle .

${ }^{14} \mathrm{C}$-carbon dioxide $\cdot$ Chloroplasts $\cdot{ }^{14} \mathrm{C}$-labelled novel compounds · Keto-group exchange $\cdot$ L-type pentose pathway - Spinach leaf . Octulose phosphates . Octulose-P epimerization - Phosphotransferase .

Revised RPP in PS · Stromal enzymes

\section{Abbreviations}

Ald

$\operatorname{Ald}_{x}$

Ara 5-P

Ara 5-P I

Chl

DHAP

Ery 4-P

FBP-ase

Fru 6-P

Gap

Gap-DH

Glc 6-P

Glc 6-PDH

Oct

D- $g$-D- $i$-oct $1,8-\mathrm{P}_{2} \quad$ D-glycero-d-ido-2-octulose 1,8-

D- $g$-D- $a$-oct $1,8-\mathrm{P}_{2} \quad$ D-glycero-D-altro-2-octulose 1,8 -

PBA

PFK

PGA

PGI

PP

PPE

PRI

PRK

PS

PT bisphosphate bisphosphate

aldolase

aldolase exchange

arabinose 5-phosphate

arabinosephosphate isomerase

chlorophyll

dihydroxyacetone phosphate

erythrose 4-phosphate

fructose 1,6-bisphosphatase

fructose 6-phosphate

glyceraldehyde 3-phosphate

glyceraldehyde 3-phosphate

dehydrogenase

glucose 6-phosphate

glucose 6-phosphate

dehydrogenase

octulose

phenylboronic acid

phosphofructokinase

3-phosphoglyceric acid

phosphoglucoseisomerase

pentose (phosphate) pathway

phosphoketopentose epimerase

phosphoribose isomerase

phosphoribulokinase

photosynthesis

phosphotransferase: D-glycero-Dido -\& D-glycero-D-altro-octulose

1,8- bisphosphate :D-altro-

heptulose 7-phosphotransferase
Rib 5-P

$\mathrm{Ru} 1,5-\mathrm{P}_{2}$

RPP

Rubisco

Seh

SBP-ase

SEP

TA

$\mathrm{Ta}_{\mathrm{x}}$

TK

$\mathrm{TK}_{\mathrm{x}}$

TPI

ThPP

Xlu 5-P ribose 5-phosphate

ribulose 1,5-bisphosphate

reductive pentose pathway (PS

path of $\mathrm{CO}_{2}$ assimilation in $\mathrm{C}_{3}$

plants)

ribulose 1,5 bisphosphate

carboxylase/oxygenase

sedoheptulose (altro-2-

ketoheptulose)

sedoheptulose 1,7- bisphosphatase

stromal enzyme preparation

transaldolase

transaldolase exchange

transketolase

transketolase exchange

triosephosphate isomerase

thiamine pyrophosphate

xylulose 5-phosphate

\section{Introduction}

The formulation of the Calvin-Benson-Bassham pathway, hereafter called Calvin cycle, of photosynthesis (PS) was heavily dependent on the elucidation of a reaction sequence for the pentose pathway (PP) of glucose metabolism in the biochemistry of tissues. A reaction sequence for the PP was proposed from the results of experiments in which liver, pea leaf and pea root enzyme preparations were used to catalyse the conversion of $\left[1-{ }^{14} \mathrm{C}\right]$ Ribose 5-P (Rib 5-P) to ${ }^{14} \mathrm{C}-\mathrm{la}-$ belled hexose 6-P and unlabelled glyceraldehyde 3-P (Gap), which were formed in vitro over a 17-h period (Horecker et al. 1954). For many years Williams and co-workers investigated and published results of research on PP in liver, some neoplasms, adipose tissue, heart, colonocytes and photosynthetic tissues (see Williams et al. 1987; Williams 2004 for published listings). These investigations showed that the conclusion drawn from the results of the fundamental experiments on which the PP reaction sequence is based (Horecker et al. 1954; Gibbs and Horecker 1954) was erroneous and because of its $17-\mathrm{h}$ duration, the results were incapable of being interpreted due to the random scattering of ${ }^{14} \mathrm{C}$ isotope in the glucose 6-P (Glc 6-P) product. The ${ }^{14} \mathrm{C}$ labelling pattern of Glc 6-P was the result of a prediction labelling experiment that was used to hypothesize a reaction sequence for the PP. The unpredictable and randomized isotope scattering of ${ }^{14} \mathrm{C}$ in Glc 6-P was finally shown to be due to the activity of the extensive ${ }^{14} \mathrm{C}$-exchange rates versus the 
slower rates of mass transfer reactions catalysed by the group transferring enzymes, aldolase (EC 4.1.2.13) (Ald), transketolase (EC 2.2.1.1) (TK) and transaldolase (EC 2.2.1.2) (TA) (Flanigan et al. 1993). Williams et al. (1978a) demonstrated that the reversible interconversions of Rib 5-P and hexose and triose phosphates by liver and the other tissues mentioned above, also involved ido- and altro-octulose mono- and bisphosphates, sedoheptulose 1,7- $\mathrm{P}_{2}\left(\right.$ Seh $\left.1,7-\mathrm{P}_{2}\right)$ and a low concentration of arabinose 5-P (Ara 5-P) as intermediates, together with a proposal for the inclusion of three new enzyme activities in the PP reaction sequence (see Fig. 1).

Calvin and colleagues based the reaction sequence which regenerated pentose phosphates (especially $\mathrm{Ru}$ $1,5-\mathrm{P}_{2}$ ) from hexose and triose phosphates in PS, on a selection of the reactions of a reverse-acting classical PP (Calvin 1956), thereby providing important credibility at the time for the PP which still carried an author-imposed tentative caveat. It was later noted (Clark et al. 1974) that the omission of the above new PP intermediates and enzymes from the Calvin scheme provided further explanations of some of the early criticisms and anomalies of the Calvin pathway scheme (Clark et al. 1974; Stiller 1962; Kandler and Gibbs 1956; Beck and Hopf 1982).

The investigations described here were made in order to (a) search for evidence that D- $g$-D- $i$-oct phosphates may be formed by carbon fixation reactions in spinach during PS and (b) quantitatively measure any formation of octulose phosphates and investigate whether their proposed path of synthesis conformed with a theoretical extension of the photosynthetic reaction scheme shown in Fig. 2. This paper reports the results of studies on the formation and functions of octulose phosphates, with a particular initial focus on D-glycero-D-ido-octulose 1,8 $\mathrm{P}_{2}$ and the 8-monophosphate, together with other novel intermediates in spinach leaves and chloroplasts.

The initial singular attention on the ido- epimer rather than an inquiry that also included D-glycero-Daltro-octulose phosphates, rested on the exclusive roles assigned to D- $g$-D- $i$-oct phosphates in the L-type PP (Fig. 1). However, a final conclusion drawn from the study suggests that both epimeric forms of octulose phosphates occur and that both may have roles in the path of carbon in PS. The investigation used the same ${ }^{14} \mathrm{C}$ tracer and other methodologies that were pioneered by Calvin and his team in the unravelling of a path of carbon in PS. The accompanying paper reports the results of a subsequent mass spectrometric investigation of the incorporation of ${ }^{13} \mathrm{CO}_{2}$ into $\mathrm{C}_{4}$ to $\mathrm{C}_{8}$ sugar phosphates in spinach chloroplasts during light-driven PS.

\section{Materials and methods}

\section{Growth of plant material}

Spinach (Spinacia oleracea, L.,var. Yates 102) was grown by water culture in a glasshouse under natural lighting
Fig. 1 The L-Type PP of glucose metabolism. The pathway features reactions of arabinose 5-phosphate, Dglycero-D-ido-octulose and sedoheptulose mono- and bisphosphates together with new enzymes to catalyse their reactions (Williams and Clark 1971; Williams et al. 1978a; Williams 2004)

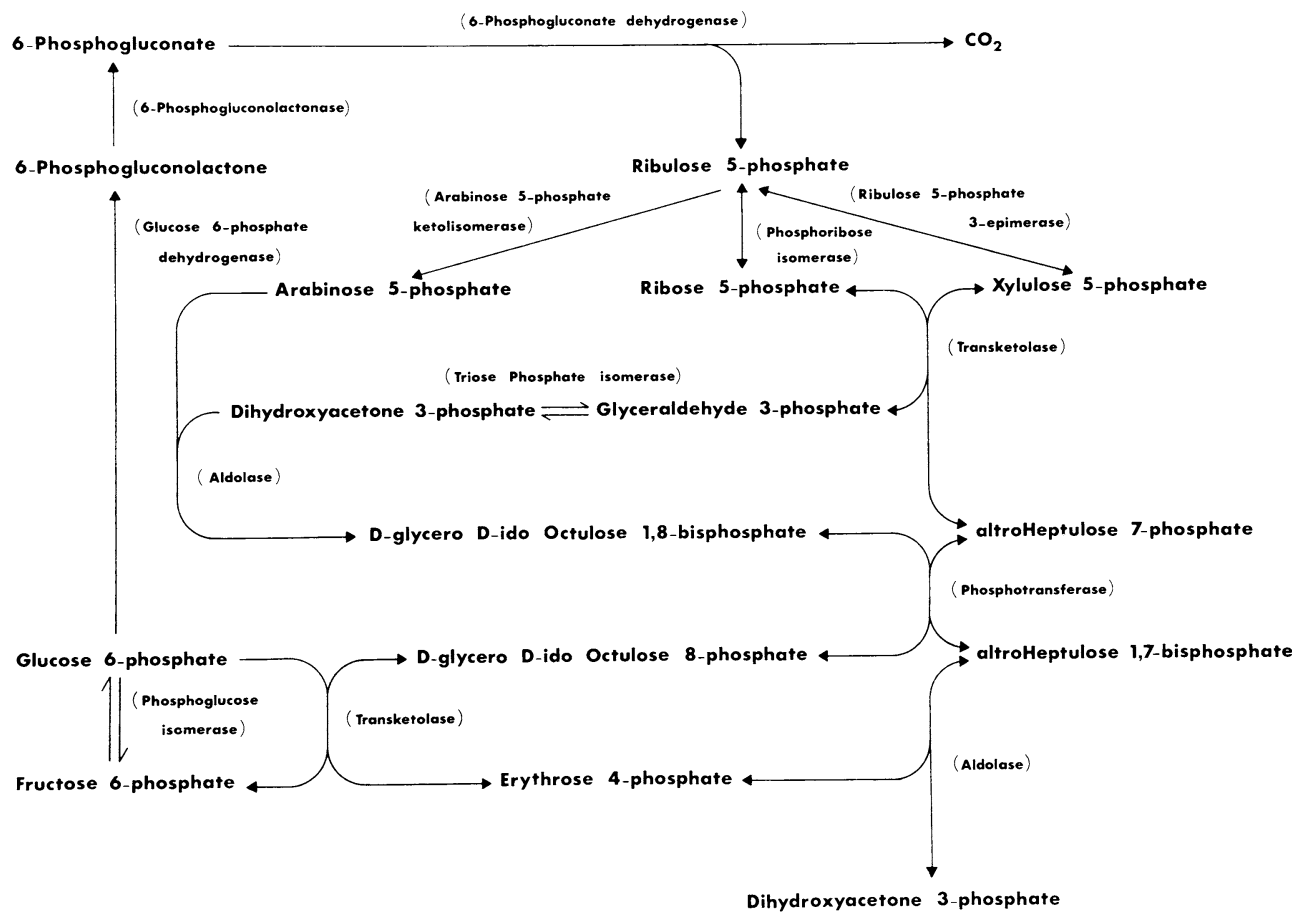


Fig. 2 The initial hypothesis for a revised reaction scheme for the reductive PP of photosynthetic carbon reduction in C-3 plants. The hypothesis differs from the Calvin Pathway by the inclusion of new enzymes and reactions by octulose and arabinose phosphates and is tested by the results reported in this paper. The figure shows the distributions (for one cycle) of the coloured carbon of $\mathrm{CO}_{2}$ into traditional and proposed new intermediates of a modified Calvin Pathway

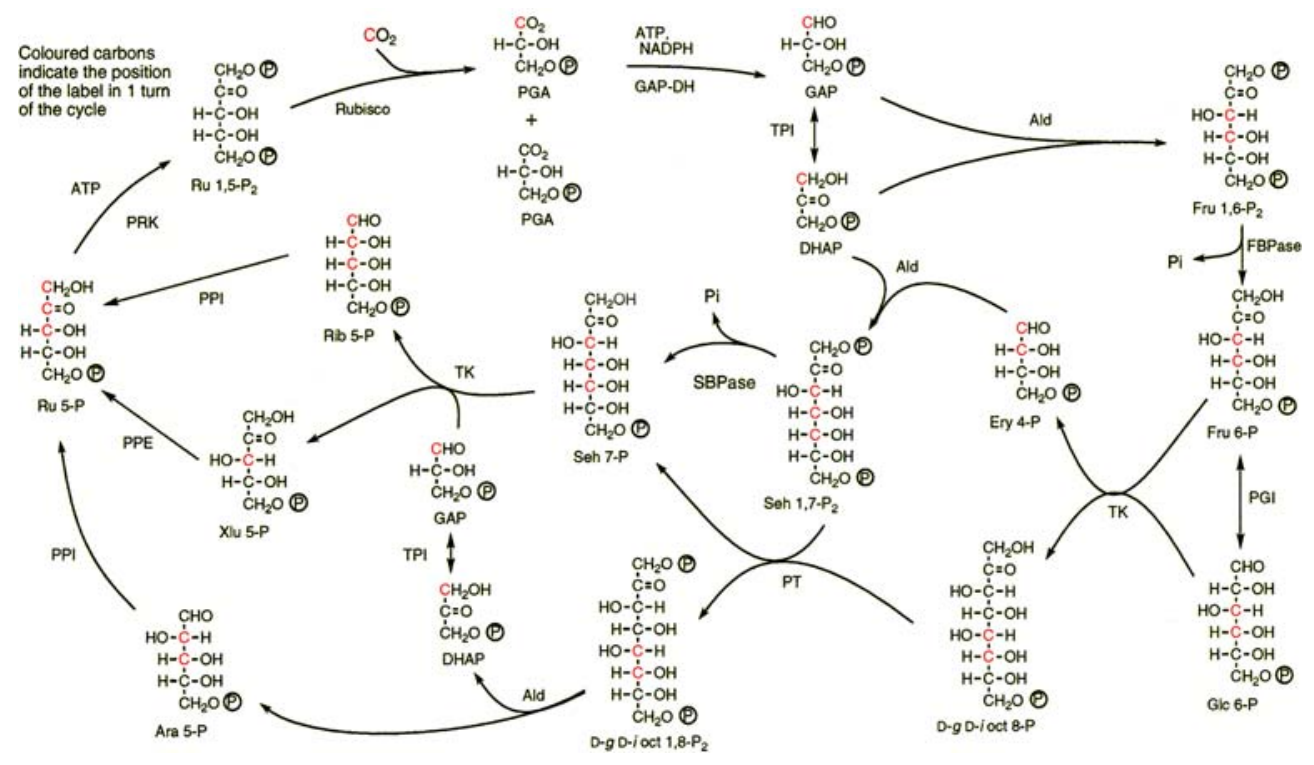

according to established methods (Anderson and Boardman 1966). Depending on the season, leaves were harvested five or eight weeks after sowing the seeds.

Chemical and chromatographic materials

Enzymes and cofactors for analysis and synthesis of sugar phosphates were obtained from either Sigma Chemical Co., St. Louis, MO 63178, USA or from Boehringer-Mannheim Corp., D-6800 Mannheim, Germany. ${ }^{14} \mathrm{C}$ - and ${ }^{32} \mathrm{P}$-labelled compounds were from Amersham (Bucks, England). Other analytical reagent grade chemicals were obtained from Ajax Chemicals, Sydney, Australia, BDH Poole, BH12 4NN, UK, or E. Merck, D-6100 Darmstad, Germany. Chromatographic media were obtained from the following sources: Ion exchange resins from BioRad, Richmond, CA 94804, U.S.A. Phenylboronate agarose gel (Matrex PBA 60) from Amicon Corp., Danvers, MA 01923, USA. Thin layer chromatography plates from E.Merck, 3Mm paper from Whatman, Maidstone, UK, Sephadex G10 and Sephadex A25 from Pharmacia, Uppsala, Sweden. Chromatographic columns were from Pharmacia or LKB, Bromma, Sweden. Ultrafiltration apparatus and Diaflow PM10 membranes were obtained from Amicon, Lexington, MA, USA.

Extraction and analysis of photosynthetic tissue metabolites by gas-liquid chromatography

Young spinach leaves (6-8 weeks) were detached from plants, which had been exposed to full sunlight for $8 \mathrm{~h}$, and then placed in liquid nitrogen. The tissue was ground to a fine powder using a stainless steel mortar and pestle and $6 \%$ perchloric acid was added. The temperature of this mixture was raised to $4{ }^{\circ} \mathrm{C}$ and the solid was blended with the acid using a Potter-Elvejhem homogenizer. The liquid was separated from insoluble matter by centrifugation at $10,000 \mathrm{~g}$ for $10 \mathrm{~min}$. The pellet was re-extracted with perchloric acid and the two extracts combined. The solution was neutralized with $2 \mathrm{M} \mathrm{KOH}$ and stored at $2^{\circ} \mathrm{C}$ for several hours to complete the precipitation of potassium perchlorate which was then removed by centrifugation at $15,000 \mathrm{~g}$ for $10 \mathrm{~min}$. The supernatant fluid was treated with acidwashed activated carbon (Norite) to remove nucleotides and aromatic compounds and was lyophilized. The extract was dissolved in $5 \mathrm{ml}$ of $0.2 \mathrm{M}$ acetate buffer, pH 5.0 and 20 units of acid phosphatase (EC 3.1.3.2 from potato $)$ added. Mannitol $(2 \mu \mathrm{mol})$ and erythritol $(0.5 \mu \mathrm{mol})$ were added as internal standards. The mixture was incubated at $30^{\circ} \mathrm{C}$ to achieve complete sugar phosphate hydrolysis. The free sugars were recovered by thermally denaturing the protein, followed by centrifugation and treatment of the supernatant fraction with a three-fold excess (calculated from the amount of buffer used) of mixed bed resin (Dowex $50 \times 4,100-200$ mesh, $\mathrm{H}^{+}$form; Dowex $1 \times 4,100-200$ mesh, $\mathrm{HCO}_{3}^{-}$form). The completeness of deonization was established using a Radiometer conductivity meter. The solution was lyophilized and stored at $-20^{\circ} \mathrm{C}$. Lyophilized extracts were converted to their TMS ethers immediately before analysis using the procedure of Williams et al. (1984). Dimethylformamide and bis-trimethylsilyltrifluoroacetamide $(50 \mu \mathrm{l}$ of each) were added and the mixture stirred for $45 \mathrm{~min}$ at $55^{\circ} \mathrm{C}$. The analyses were carried out using a Pye-Unicam gas chromatograph (series 204), fitted with two glass 
columns $(180 \mathrm{~cm} \times 0.4 \mathrm{~cm})$ packed with $3 \% \mathrm{SP}-2250$ on 100/120 mesh Supelco, Bellefonte, PA; USA. FID responses were recorded on a computing integrator (Spectra-Physics, model 4100).

Photosynthesis experiments with whole spinach leaves

${ }^{14} \mathrm{C}$ isotope tracer and pulse-chase investigations with whole spinach leaves were conducted using an exact application of the methods and apparatus described by Hatch and Slack (1966). This procedure and the method for the ethanol extraction, preparation of the soluble fraction and isolation of sugar phosphates was described by Bartlett et al. (1989). Sugar phosphates were separated by formate anion-exchange chromatography and further purified using two-dimensional TLC or paper chromatography and the GW3/GW3phenylboronate solvents (Kapuscinski et al. 1985). The insoluble residue remaining after ethanol extraction of all sugar phosphates was extensively washed with water, ethanol and acetone. The amount of ${ }^{14} \mathrm{C}$ radioactivity in the insoluble glucan was determined using liquid scintillation counting (Arora et al. 1987).

\section{Preparation of whole leaf homogenate}

Approximately $50 \mathrm{~g}$ of fresh spinach leaves were washed briefly in distilled water, de-ribbed and cut into small segments to facilitate maceration. The material was homogenized in $100 \mathrm{ml}$ of $50 \mathrm{mM}$ Tris- $\mathrm{HCl}$ buffer (pH 7.4) containing $1 \mathrm{mM}$ EDTA, and strained through two layers of Miracloth (Calbiochem). After centrifugation at $10,000 \times g$ for $15 \mathrm{~min}$, the preparation was concentrated four-fold by ultrafiltration using a 10,000 MW cut-off membrane (PM10 Amicon). The concentrated solution was dialysed for $10 \mathrm{~h}$ against six changes of the homogenization buffer. All operations were carried out at $4^{\circ} \mathrm{C}$.

\section{Chloroplast isolation}

The procedure for the isolation of intact chloroplasts is based on a method which involves a two-step gradient of the silica-sol, Percoll (Pharmacia Biotech, Sweden) (Robinson 1983). Five- to six-weeks-old spinach leaves were harvested in the early morning in order to avoid the accumulation of starch granules, which can rupture the chloroplast envelope during centrifugation. The amount of leaf material required to produce a satisfactory yield of chloroplasts was not critical but the yield depended on the quality of the leaves and increased with the amount of material used. The harvested leaves were de-ribbed and floated in basins of water. Immediately before isolating the chloroplasts, the leaves were illuminated for $30 \mathrm{~min}$ with incandescent light at an intensity of $800 \mu \mathrm{E} \mathrm{m}^{-2} \mathrm{~s}^{-1}$. During this period, crushed ice was added to the water to maintain the temperature at $15^{\circ} \mathrm{C}$. Typically, $55 \mathrm{~g}$ of coarsely chopped leaves were homogenized in $300 \mathrm{ml}$ of medium for 1.5-2 s using a Polytron blender (setting 7) fitted with a PT35K probe. The homogenizing medium at $\mathrm{pH} 6.5$ was chilled to a semi-frozen consistency before use and contained $330 \mathrm{mM}$ sorbitol, $10 \mathrm{mM} \mathrm{Na}_{4} \mathrm{P}_{2} \mathrm{O}_{7} \cdot 10 \mathrm{H}_{2} \mathrm{O}, 5 \mathrm{mM} \mathrm{MgCl}, 2 \mathrm{mM}$ isoascorbic acid and $0.1 \%$ bovine serum album (BSA) (Jensen and Bassham 1966). The brei was filtered through a double layer of Miracloth (Calbiochem). The filtrate was centrifuged at $1,200 \times g$ for $1 \mathrm{~min}$ in a Sorvall refrigerated centrifuge (DuPont Medical Products, Newtown, CT O647-5509 USA) using either an SS34 or SA600 rotor. The supernatant fluid was discarded and the sedimented material was gently resuspended, using a fine soft brush, in $6 \mathrm{ml}$ of a medium at $\mathrm{pH} 7.6$ containing $330 \mathrm{mM}$ sorbitol, $50 \mathrm{mM}$ HEPES-KOH, $2 \mathrm{mM}$ EDTA, $1 \mathrm{mM} \mathrm{MgCl}_{2}$ and $1 \mathrm{mM}$ $\mathrm{MnCl}_{2}$ (Jensen and Bassham 1966). An aliquot (3 ml) of the suspension was then placed into each of two 40$\mathrm{ml}$ Corex tubes and carefully underlaid with $4 \mathrm{ml}$ of Percoll medium made to $40 \%$ with resuspension medium and centrifuged. Finally, the chloroplasts were suspended in the resuspension medium $(3 \mathrm{ml})$ and stored on ice. The above procedures were carried out on ice using previously chilled equipment. All parameters (density, yield, photosynthetic activity etc.) describing chloroplast properties were related to the Chl content measured according to the following procedure. Twenty five to $65 \mathrm{~g}$ of leaves produced between $3 \mathrm{mg}$ and $8 \mathrm{mg}$ of Chl. Provided the quality of leaf material was satisfactory and the Percoll was fresh, the method unfailingly produced a maximum yield of highly active chloroplasts which were better than $95 \%$ intact. Typical examples of preparations had the following mean values and S.D.: Activity $113.7 \pm 8.6$ ( $n=10) \mu \mathrm{mol} \mathrm{CO} \mathrm{h}^{-1} \mathrm{mg}^{-1} \mathrm{Chl}$; Intactness $95.75 \% \pm$ $3.25 \%(n=10)$.

\section{Chlorophyll assay}

The Chl content of isolated chloroplast suspensions was estimated by the method of Arnon (1949). In whole leaf experiments Chl was estimated using the method of Vernon (1960). 
Measurements of chloroplast polarographic activity and intactness

The activity of the isolated chloroplast suspensions was determined polarographically using a Clark oxygen electrode. The reaction mixture $(2 \mathrm{ml})$ contained,

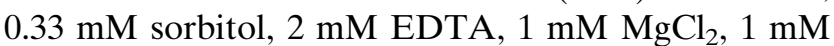
$\mathrm{MnCl}_{2}, 50 \mathrm{mM}$ HEPES, $0.5 \mathrm{mM} \mathrm{P}_{\mathrm{i}}, 5 \mathrm{mM}$ pyrophosphate, 500 units of catalase (EC 1.11.1.6), $10 \mathrm{mM}$ $\mathrm{NaHCO}_{3}$ and chloroplast suspension equivalent to $40 \mu \mathrm{g}$ of $\mathrm{Chl}$. The $\mathrm{CO}_{2}$-dependent $\mathrm{O}_{2}$ evolution of isolated chloroplast suspensions illuminated in an assay medium at $20^{\circ} \mathrm{C}$ was recorded using a Goerz Metrawatt SE120 chart recorder and the rate of oxygen evolution was calculated from the linear portion of the trace. The chloroplasts were illuminated at an intensity of $1,200 \mu \mathrm{E} \mathrm{m}^{-2} \mathrm{~s}^{-1}$ using the quartz-halogen light from a slide projector. In the experiments described here, the range of acceptable activity of chloroplast preparations is $100-120 \mu \mathrm{mol} \mathrm{h}^{-1} \mathrm{mg}^{-1}$ Chl. Light measurements were made using a Hansatech Quantum Sensor 3/2897 (Hansatech Instruments, King's Lynn, Norfolk PE321, JL.UK).

The intactness of chloroplasts was measured by the ferricyanide reduction method (Lilley et al. 1975).

Isotopic tracer studies with isolated chloroplasts

Experiments were carried out in the oxygen electrode (unless stated otherwise) by the procedure described for the assay of chloroplast activity. $\mathrm{NaH}^{14} \mathrm{CO}_{3}$ $(100 \mu \mathrm{Ci})$ was introduced when the rate of $\mathrm{CO}_{2^{-}}$ dependent oxygen evolution reached a linear rate. The reaction was terminated by rapid transfer of the mixture to boiling ethanol $(80 \% \mathrm{w} / \mathrm{v})$. The insoluble material was removed by centrifugation and washed once with a small volume of water. The ethanol was evaporated from the combined supernatant solutions in a rotary evaporator. After passage through a cationexchange column (Bartlett et al. 1989), the sugar phosphates were separated and isolated by anion-exchange column chromatography and further purified by two-dimensional TLC or paper chromatography (Kapuscinski et al. 1985).

The isolation of stromal metabolites used the method of Heldt (1980) which relied on rapid separation of intact chloroplasts from a reaction medium using the following silicon oil method. Fifty $\mu \mathrm{l}$ of $10 \mathrm{M}$ formic acid and $50 \mu \mathrm{l}$ of silicone oil mixture (AR100 and AR150 mixed in a ratio of 3:1) were placed in a 400- $\mu \mathrm{l}$ microfuge tube followed by $200 \mu \mathrm{l}$ of a chloroplast suspension that had been preincubated with ${ }^{32} \mathrm{P}$-orthophosphate (specific radioactivity $50 \mathrm{mCi} \mathrm{mmol}^{-1}$ ).
The extracts of the pellets containing the aqueous fractions that were pooled from four tubes were lyophilized and the sugar phosphates therein were isolated by anion-exchange column chromatography as described in Methods. Sugar phosphate peaks isolated in the column eluates were identified and quantitatively measured using the specific enzymatic and colourimetric procedures of Williams et al. (1978b) and Kapuscinski et al. (1985).

Preparation of stromal enzyme extracts (SEP) from spinach chloroplasts

The soluble (stromal) enzyme fraction was prepared essentially as described by Furbank and Lilley (1981) for pea chloroplasts. Intact spinach chloroplasts were isolated with assayed rates of $\mathrm{CO}_{2}$-dependent $\mathrm{O}_{2}$ evolution in excess of $100 \mu \mathrm{mol} \mathrm{h}^{-1} \mathrm{mg}^{-1}$ Chl. Typically a chloroplast suspension equivalent to $2 \mathrm{mg}$ of $\mathrm{Chl}$ was pelleted by centrifugation at $1,000 \times g$ for $1 \mathrm{~min}$ in an SS34 Sorvall rotor at $4^{\circ} \mathrm{C}$. The supernatant solution was removed and $10 \mathrm{ml}$ of chilled $10 \mathrm{mM}$ HEPES buffer, $\mathrm{pH} 8.0$ containing $3 \mathrm{mM}$ DTT was added. The pellet was resuspended by gentle shaking. The centrifuge tube was kept on ice for approximately $10 \mathrm{~min}$ after which it was centrifuged for $15 \mathrm{~min}$ at $9,000 \times \mathrm{g}$ in a refrigerated Sorvall centrifuge RC-5 to separate the soluble proteins from the membrane fraction. The clear supernatant fluid, representing the stromal fraction of the chloroplasts, was concentrated to $4 \mathrm{ml}$ in an Amicon ultrafiltration cell, using a PM10 membrane (nominal MW cut-off 10,000). Finally, dialysis was carried out against $3 \times 500 \mathrm{ml}$ of dialysis buffer containing $10 \mathrm{mM}$ HEPES-KOH (pH 8.0), $3 \mathrm{mM}$ DTT, $15 \mathrm{mM} \mathrm{MgCl} 2$ and $10 \mathrm{mM} \mathrm{KCl}$. This last step was completed in $4 \mathrm{~h}$. The pelleted membranes were retained for $\mathrm{Chl}$ analysis. The activity of the extracts was stable for $4-6 \mathrm{~h}$ from completion of the dialysis step. Some experiments used an alternative stromal isolation procedure based on the method of Kaiser and Bassham (1979). The chloroplast suspension was pelleted as described above but lysis of organelles was achieved with $25 \mathrm{mM}$ HEPES-NaOH, $2 \mathrm{mM} \mathrm{MgCl}_{2}$, $1 \mathrm{mM}$ EDTA ( $\mathrm{pH}$ 7.6) and the same buffer was used for dialysis.

Assay of the reductive PP using stromal enzyme preparation (SEP)

The activity of the reductive PP in the stromal extracts was determined by the method of Furbank and Lilley (1981). The progress of the reaction was followed spectrophotometrically using $0.2-\mathrm{cm}$ light path cuvettes. 
The assay mixture contained $40 \mathrm{mM}$ HEPES-KOH buffer (pH 8.0), $20 \mathrm{mM} \mathrm{MgCl}_{2}, 8 \mathrm{mM} \mathrm{KCl}, 1 \mathrm{mM}$ NADH, $0.8 \mathrm{mM}$ EDTA, $10 \mathrm{mM}$ DTT, $4 \mathrm{mM}$ ATP, $10 \mathrm{mM}$ creatine phosphate, $10 \mathrm{mM} \mathrm{NaHCO}_{3}, 2$ units of creatine kinase (EC 2.7.3.2), 1.25 units of glyceraldehyde-phosphate dehydrogenase (EC 1.2.1.12), 1.7 units of phosphoglycerate kinase (EC 2.7.2.3). SEP equivalent to 5-50 $\mu \mathrm{g}$ of $\mathrm{Chl}$ was added to make a final volume of $500 \mu \mathrm{l}$. SEP was preincubated for $5 \mathrm{~min}$ at $25^{\circ} \mathrm{C}$ in $20 \mathrm{mM} \mathrm{MgCl} 2,10 \mathrm{mM}$ DTT, $10 \mathrm{mM} \mathrm{NaHCO}$ before addition of the test sugar phosphate substrate. Usually the following test substrates were individually used at $2 \mathrm{mM}$ concentration in the reaction mixture: Rib 5-P, dihydroxyacetonephosphate (DHAP), or Seh 1,7- $\mathrm{P}_{2}$.

Maximum catalytic capacity of the non-oxidative segment of the PP

This was determined by following the conversion of ribose 5-P to hexose 6-P in a coupled enzyme assay as described by Williams et al. (1984). The reaction mixture contained $80 \mathrm{mM}$ TEA-HCl buffer, $\mathrm{pH} 7.4$, $0.4 \mathrm{mM} \mathrm{NADP}{ }^{+}, 10 \mathrm{mM} \mathrm{MgCl} 2,1.5$ units of phosphoglucose isomerase (EC 5.3.1.9) (PGI), 2 units of glucose 6-phosphate dehydrogenase (EC 1.1.1.49) (Glc 6-PDH), $0.4 \mathrm{mM}$ ribose 5-P and stromal extract equivalent to $50 \mu \mathrm{g}$ of $\mathrm{Chl}$ in a total volume of $1.0 \mathrm{ml}$.

Synthesis of isotopically labelled compounds

[U- $\left.{ }^{14} \mathrm{C}\right]$ Arabinose 5-phosphate, $\left[8-{ }^{14} \mathrm{C}\right] \mathrm{D}-g$-D- $a$-oct 8-P and $\left[8-{ }^{14} \mathrm{C}\right] \mathrm{D}-g$-D- $i$-oct 8 -P were prepared by the method of Arora et al. (1987). [1 $\left.1{ }^{32} \mathrm{P}\right]$-Sedoheptulose 1,7-bisphosphate was prepared by phosphorylation of sedoheptulose 7-P (altro-heptulose) with $\left[\gamma^{32} \mathrm{P}\right]$ ATP using rabbit muscle phosphofructokinase (EC 2.7.1.11) $(\mathrm{PFK})$. The reaction mixture $(0.50 \mathrm{ml})$ contained: $20 \mu \mathrm{mol}$ Tris-HCl buffer (pH 7.6), $2.5 \mu \mathrm{mol}$ of $\mathrm{MgCl}_{2}$, $0.2 \mu \mathrm{mol}$ of $\left[\gamma_{-}{ }^{32} \mathrm{P}\right]$ ATP $(100 \mu \mathrm{Ci}), 2.5 \mu \mathrm{mol}$ of Seh 7-P and 6 units of PFK. The mixture was incubated at $25^{\circ} \mathrm{C}$ and was $95 \%$ complete in $1 \mathrm{~h}$. The title compound was purified using formate-anion exchange chromatography and TLC as described above and was shown by enzymatic analysis to be free of Fru 1,6- $\mathrm{P}_{2}$. Unlabelled D-glycero-D-ido- and D-glycero-D-altro-octulose 8-P and $1,8-\mathrm{P}_{2}$ esters were prepared as described in Kapuscinski et al. (1985).

Measurements of phosphotransferase activity

Arora et al. (1985) published three assay procedures for the minimum estimate of the activity of D-glycero-
D-ido-octulose $1,8-\mathrm{P}_{2}$ or D-glycero-D-altro-octulose 1,8 $\mathrm{P}_{2}$ : D-altro-heptulose 7-phosphotransferase (PT). Two of these assays measured the reaction for the nonoxidative PP (Fig. 1) in the direction of octulose 8-P formation. The third procedure, and the one detailed here, measured the activity in the flux direction of the RPP (see Fig. 2 and Eqs. (1) and (2)).

$$
\begin{aligned}
& {\left[8-{ }^{14} \mathrm{C}\right] \text {-D- } g \text {-D- } i \text {-oct } 8-\mathrm{P}+\mathrm{Seh} 1,7-\mathrm{P}_{2}} \\
& \quad \longleftrightarrow \text { Seh 7-P }+\left[8-{ }^{14} \mathrm{C}\right] \text {-D- } g \text {-D- } i \text {-oct } 1,8-\mathrm{P}_{2} \\
& {\left[8{ }^{14} \mathrm{C}\right]-\mathrm{D}-g \text {-D- } a \text {-oct } 8-\mathrm{P}+\mathrm{Seh} 1,7-\mathrm{P}_{2}} \\
& \quad \longleftrightarrow \text { Seh 7-P }+\left[8-{ }^{14} \mathrm{C}\right]-\mathrm{D}-g \text {-D- } a \text {-oct } 1,8-\mathrm{P}_{2}
\end{aligned}
$$

Only the third method was effective when SEP was the crude source of the putative enzyme activity. It is a radiochromatographic discontinuous-stop assay and is applied as follows. The reaction mixture in a volume of $0.50 \mathrm{ml}$ contained $1 \mu \mathrm{mol}$ of $\left[8-{ }^{14} \mathrm{C}\right]$-octulose $8-\mathrm{P}$ $\left(0.8 \mu \mathrm{Ci} \mu \mathrm{mol}^{-1}\right), 3 \mu \mathrm{mol}$ Seh $1,7-\mathrm{P}_{2}, 20 \mu \mathrm{mol}$ of TEA$\mathrm{HCl}$ buffer (pH 7.4) and $16 \mu \mathrm{mol}$ of $\mathrm{KCl}$. The mixture was incubated for $30 \mathrm{~min}$ at $30^{\circ} \mathrm{C}$ and was initiated by the addition of SEP equivalent to $50 \mu \mathrm{g}$ of Chl. Aliquots $(0.1 \mathrm{ml})$ were sampled at $5.0 \mathrm{~min}$ intervals during the time-course of the reaction and injected into an equal volume of $6 \%$ perchloric acid. Denatured protein was removed by centrifugation, the $\mathrm{pH}$ of the supernatant fluid adjusted to 6.8 with $\mathrm{KOH}$ and precipitated $\mathrm{KClO}_{4}$ separated by centrifugation. The activity of the enzyme was estimated by separating the labelled octulose mono- and bis-phosphates by ionexchange chromatography as follows: A precisely known volume of the above supernatant fraction was applied onto a column $(5 \mathrm{~mm} \times 5 \mathrm{~mm})$ of ion-exchange resin (AG 1 X8, 200-400 mesh, formate form) followed by $2 \mathrm{ml}$ of deionized water. The sugar phosphates were eluted by successive washes with $2 \mathrm{M}$ $\mathrm{HCOOH}$ (approx. $12 \mathrm{ml}$ ), which quantitatively removed monophosphate esters, and $5 \mathrm{ml}$ of $4 \mathrm{M}$ HCOOH-1 $\mathrm{M} \mathrm{HCOONH}{ }_{4}$ solution which eluted sugar bisphosphates. Fractions $(2 \mathrm{ml})$ of the eluted sugar phosphates at each time point were analysed for radioactivity and the amount of octulose bisphosphate formed was calculated from the integrated peaks of radioactivity. Confirmation of the identity and amount of radioactivity in the ${ }^{14} \mathrm{C}$-labelled octulose phosphates used two-dimensional radiochromatography of each of the above fractions and the GW3/GW3-phenylboronate solvents (Kapuscinski et al. 1985). Control experiments using only a single substrate accompanied each activity measurement. 
Arabinose 5-P activity with SEP

The reaction mixture $(2.0 \mathrm{ml})$ containing $80 \mu \mathrm{mol}$ TEA-HCl buffer (pH 7.4), $3.6 \mu \mathrm{mol} \mathrm{Rib} \mathrm{5-P,} 0.4 \mu \mathrm{mol}$ of $\left[\mathrm{U}_{-}{ }^{14} \mathrm{C}\right]-\mathrm{Ara}$ 5-P $(0.2 \mu \mathrm{Ci})$ and SEP equivalent to $200 \mu \mathrm{g}$ of $\mathrm{Chl}$ was incubated for $1 \mathrm{~h}$ at $30^{\circ} \mathrm{C}$. The reaction was terminated by heating and all sugar phosphates were isolated with greater than $90 \%$ recovery of ${ }^{14} \mathrm{C}$ isotope. An identical control reaction using boiled SEP accompanied all incubations. Processed samples were chromatographed on paper using either the GW3 or GW3-2\% PBA solvents and the chromatograms exposed to X-ray film (Kodak X-O mat RP), (Bleakley et al. 1984).

Positional isotopic analysis of sugar phosphates

Following PS experiments with leaves or chloroplasts, ${ }^{14}$ C-labelled Glc 6-P, Rib 5-P, D-g-D- $i$-oct 1,8- $\mathrm{P}_{2}$ and PGA were isolated, resolved by ion-exchange chromatography and purified by two-dimensional TLC or paper chromatography. The fraction containing Glc 6-P was concentrated and chromatographed twice on paper (3MM, Whatman) using the GW3 solvent of Wood (1968) followed by solvent A of Bandurski and Axelrod (1951). The ${ }^{14} \mathrm{C}$-labelled Glc 6-P was located by autoradiography and comparison with a stained standard marker compound (Rosenberg 1959) and was then eluted from the paper with deionized water. The above regime ensured that the isolated ${ }^{14} \mathrm{C}$-labelled Glc 6-P was free of any other hexose phosphates. The phosphate group of Glc 6-P was removed by enzymatic hydrolysis as follows: Solid Glc 6-P was dissolved in $5 \mathrm{ml}$ of $50 \mathrm{mM}$ glycine- $\mathrm{NaOH}$ buffer, $\mathrm{pH} 10.4$ and 5 units of Alkaline phosphatase (EC 3.1.3.1) from Escherichia coli was added and the mixture incubated at $37^{\circ} \mathrm{C}$. The progress of the reaction was monitored by assaying the release of inorganic phosphate using the method of Tashima and Yoshimura (1975).

When the reaction was completed the mixture was poured into a suspension of mixed-bed resin (1 meq of Dowex $50 \mathrm{~W}, \mathrm{H}^{+}$form and $1 \mathrm{meq}$ of Bio AG1 x 4, $\mathrm{HCO}_{3}^{-}$form) which was stirred for approx. $60 \mathrm{~min}$. The solution was filtered through a sintered glass funnel (porosity 3 ) and the residual cake of resin thoroughly washed with deionized water. The ${ }^{14} \mathrm{C}$-labelled glucose filtrate was freeze-dried and stored at $4^{\circ} \mathrm{C}$ until used. The percentage distribution of ${ }^{14} \mathrm{C}$ isotope in the individual carbons of glucose was determined as ${ }^{14} \mathrm{CO}_{2}$ using a combination of microbiological and chemical methods (Williams et al. 1971).

${ }^{14} \mathrm{C}$-Labelled octulose phosphates from spinach leaves or chloroplast extracts were isolated and puri- fied as above and degraded using the methods of Williams et al. (1985). Following isolation by anionexchange and TLC chromatography, ${ }^{14} \mathrm{C}$-labelled Rib- and Ara 5-phosphates were dephosphorylated (Williams et al. 1984) and Ara and Rib were chemically degraded using the periodate method (Genovese et al. 1970). $\left[{ }^{14} \mathrm{C}\right]-3$-Phosphoglyceric acid derived from DHAP was chemically degraded by the procedure of Andrews et al. (1965).

Recovery of ${ }^{14} \mathrm{CO}_{2}$ as $\mathrm{BaCO}_{3}$ and measurement of radioactivity

Discs $(2 \mathrm{~cm})$ of Whatman No. 42 filter paper were used to collect barium carbonate precipitates. The discs were washed with water, absolute ethanol and diethyl ether, dried and weighed before use. $\mathrm{BaCO}_{3}$ was deposited on the papers using gentle suction, then washed with $\mathrm{CO}_{2}$-free water, alcohol and ether. The discs were dried under vacuum over silica and equilibrated at room temperature before weighing on a semi-micro balance. Approx. $20 \mathrm{mg}$ of dried $\mathrm{BaCO}_{3}$ was exactly weighed, placed into a vial with $10 \mathrm{ml}$ of scintillation cocktail and counted for radioactivity as a suspension in the "Cab-O-Sil" (Godfrey L. Cabot Inc.) scintillant of Cluley (1962).

\section{Replication and statistical analysis}

Data presented are the mean values $( \pm$ S.D. $)$ from results of five or more experiments or mean values ( \pm P.E.) (Probable Error) for all experiments conducted on different days.

\section{Results and discussion}

GLC analysis of perchloric acid extracts of spinach leaves

Principal aims of the experiments were an investigation of the occurrence, identity and quantitative levels of the ido- and altro-octuloses in fresh photosynthetic tissue and the assessment of their hypothesized functions (especially that of $\mathrm{D}-g$-D- $i$-oct $1,8-\mathrm{P}_{2}$ ) in PS. It was noted that Charlson and Richtmyer (1959) and Begbie and Richtmyer (1966) had isolated and characterized octulose from avocado and Primula officinalis, respectively. In a remarkable finding Howarth et al. (1996) showed that D-glycero-D-ido-octulose represented $90 \%$ of the total carbohydrates in fully hydrated leaves and $50 \%$ of dried leaf matter of the resurrection plant Craterostigma plantagineum. Heath (1984) also 
showed evidence for the L-type, but not the F-type, PP in Chlorella sorokiniana. Since the mono- and bisphosphate esters of $\mathrm{D}-g$-D-i-oct are a unique feature of the L-type PP (Fig. 1), the need to identify and measure these esters in fresh spinach leaf and chloroplasts is obvious. Different methods were used to establish whether D-glycero-D-ido-octulose $1,8-\mathrm{P}_{2}$ occurred in spinach leaves. The first approach used the simple and sensitive GLC method. A gas chromatogram of the pertrimethylsilyl (TMSi) derivatives of the dephosphorylated sugar phosphates extracted from spinach leaves is shown in Fig. 3.

The high molecular weight region was well resolved and allowed tentative identification (by retention times and co-chromatography with authentic compounds) of D- $g$-D- $i$-octulose and its 5 -altro-epimer, D- $g$-D- $a$-oct. Estimation of the amounts of these compounds from the known response factors of the gas chromatograph gave values of $11.8 \pm 0.98 \mathrm{nmol} \mathrm{mg}^{-1} \mathrm{Chl}$ for idooctulose and $18.2 \pm 0.78 \mathrm{nmol} \mathrm{mg}^{-1} \mathrm{Chl}$ for altrooctulose. These values are tentative because other compounds may co-elute with the octuloses, e.g. the TMS ethers of heptitols have similar retention times to those of eight carbon sugars. In addition, the GLC method used in this study cannot differentiate between free and phosphorylated sugars. Different approaches were therefore adopted to determine the levels of specifically phosphorylated octuloses present in photosynthesizing tissue.

${ }^{14} \mathrm{C}$-D- $g$-D- $i$-oct $1,8-\mathrm{P}_{2}$ isolation from spinach leaves:
${ }^{14} \mathrm{CO}_{2}$ fixation and pulse-chase studies

The second approach used the combination of formate ion-exchange chromatography followed by phenylboronic acid and two-dimensional TLC, to achieve isolation, identification and complete separation of $\mathrm{D}-g$-D- $i$-oct $1,8-\mathrm{P}_{2}$ from all other sugar phosphates (see Methods). This methodology both confirmed and extended the GLC findings and unequivocally demonstrated that D- $g$-D-i-oct $1,8-\mathrm{P}_{2}$ occurred in spinach leaf extracts.

The conditions adopted for the study of the timecourse of ${ }^{14} \mathrm{CO}_{2}$ fixation into the products of PS involved an exact application of the method of Hatch and Slack (1966). This provided steady-state conditions for PS in intact spinach leaves at a $\mathrm{CO}_{2}$ concentration of $470 \mathrm{ppm}$ that followed from a $50 \mathrm{ml}$ injection of $0.80 \mathrm{mCi}$ of ${ }^{14} \mathrm{CO}_{2}$ and light intensity of $50 \%$ direct sunlight $\left(1,200 \mu \mathrm{E} \mathrm{m}^{-2} \mathrm{~s}^{-1}\right)$. The rate of ${ }^{14} \mathrm{CO}_{2}$ incorporation into the soluble leaf fraction (an index of the total ${ }^{14} \mathrm{CO}_{2}$ fixed) was approximately linear $(1.9 \times$ $10^{6} \mathrm{cpm} \mathrm{s}^{-1} \mathrm{mg}^{-1} \mathrm{Chl}$ ) during a 120 -s interval (Fig. 4, panel A). The ${ }^{14} \mathrm{C}$ labelling of PGA was marginally more rapid and extensive than that of Glc 6-P which reached ${ }^{14} \mathrm{C}$ isotope saturation in the interval $75-120 \mathrm{~s}$.

Glc 6-P was labelled at an approx rate of $2.8 \times 10^{5} \mathrm{cpm} \mathrm{s}^{-1} \mathrm{mg}^{-1} \mathrm{Chl}$ (Fig. 4, Panel A). The radioactivity in PGA and Glc 6-P was an order of magnitude greater than that fixed in all other sugar phosphates investigated (see Fig. 4, panel B). The fast rate of ${ }^{14} \mathrm{C}$ incorporation into $\mathrm{Rib} 5$-P was initially inclined to linear for $75 \mathrm{~s}\left(2.0 \times 10^{4} \mathrm{cpm}^{-1} \mathrm{mg}^{-1} \mathrm{Chl}\right)$. The bisphosphates Seh 1,7- $\mathrm{P}_{2}$ and $\mathrm{D}-\mathrm{g}$-D-i-oct $1,8-\mathrm{P}_{2}$ were more slowly labelled at $7.3 \times 10^{3}$ and $2.4 \times 10^{3} \mathrm{cpm} \mathrm{s}^{-1} \mathrm{mg}^{-1} \mathrm{Chl}$, respectively. The kinetics and relative degree of ${ }^{14} \mathrm{C}$ isotope incorporation into individual PS intermediates shown at Fig. 4 are very similar to the results for ${ }^{14} \mathrm{CO}_{2}$ incorporation in Scenedesmus (Benson et al. 1952). Moreover, D- $g$-D- $i$-oct 1 , $8-\mathrm{P}_{2}$ was labelled early and was saturated with ${ }^{14} \mathrm{C}$
Fig. 3 Gas liquid chromatogram of dephosphorylated TMSiderivatized sugars extracted from young spinach leaves during light-driven carbon fixation. Octuloses and arabinose feature in the chromatogram. For details see Materials and methods section

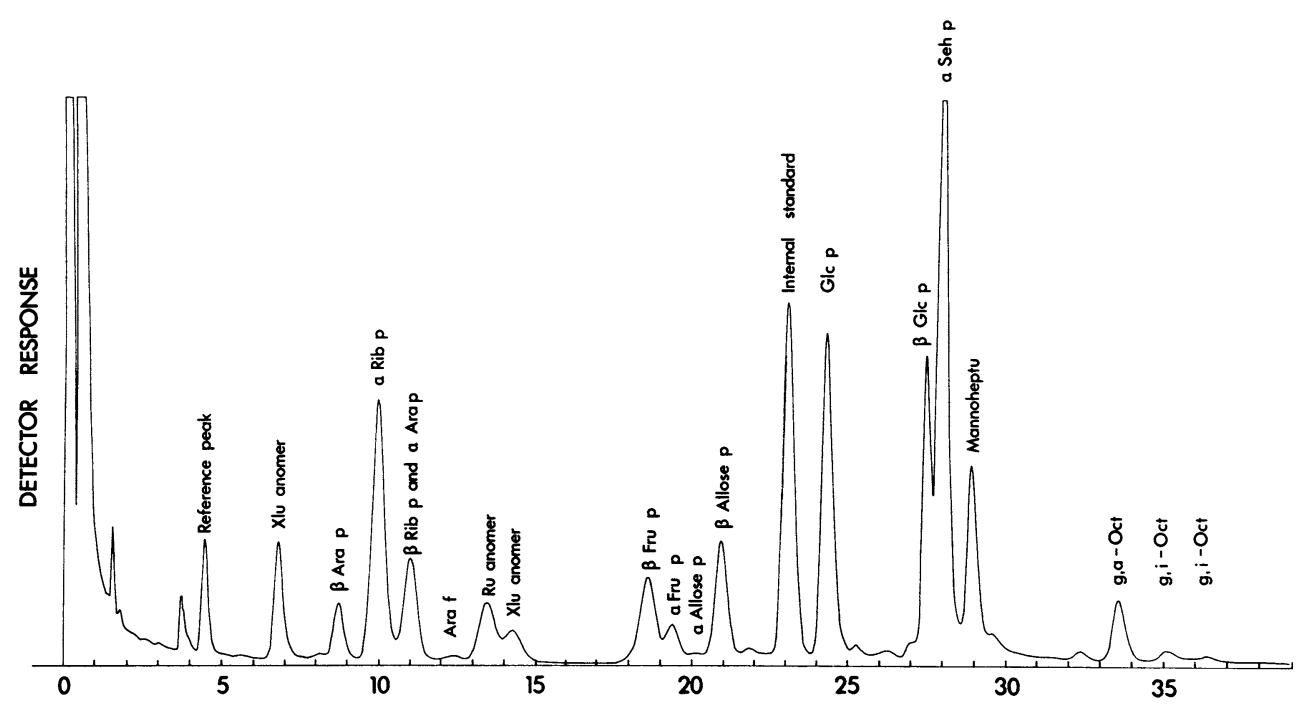




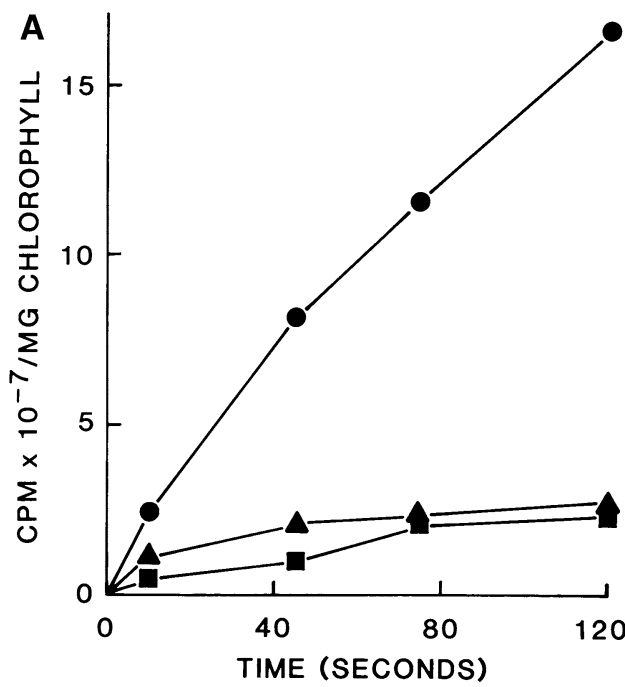

Fig. 4 Shows the kinetics of ${ }^{14} \mathrm{C}$ isotope incorporation from ${ }^{14} \mathrm{CO}_{2}$ into a selection of sugar phosphates in whole spinach leaves during light-driven PS for $120 \mathrm{~s}$. The time course of the total ${ }^{14} \mathrm{C}$ fixed in the soluble fraction of the leaf extract is also shown. Labelled sugar phosphates were resolved by anionexchange chromatography and were then individually isolated and further purified by two-dimensional paper or TLC chroma-

isotope at $75 \mathrm{~s}$, at which point its concentration in the leaf was $1.6 \mathrm{nmol} \mathrm{mg}{ }^{-1} \mathrm{Chl}$ and the rate of label incorporation was $0.13 \%$ of that fixed in the soluble fraction. When the above experiments were conducted in the dark the distribution of ${ }^{14} \mathrm{C}$ in the leaf soluble fraction was uneven and at $120 \mathrm{~s}$ was only $0.01 \%$ of that measured in the light. None of the sugar phosphates shown at the A and B panels of Fig. 4 were dark labelled.

Hatch and Slack (1966) described an apparatus for measurements of the kinetics of ${ }^{14} \mathrm{CO}_{2}$ fixation and ${ }^{12} \mathrm{CO}_{2}$ exchange by pulse-chase in bulk samples of intact leaves undergoing PS. Their method was able to delineate Calvin Cycle intermediates, which rapidly exchanged ${ }^{14} \mathrm{C}$ for ${ }^{12} \mathrm{C}$ during and following a short pulse with ${ }^{12} \mathrm{CO}_{2}$, thereby identifying rapidly cycling compounds. These are clearly distinguished by their delabelling kinetics (Figs. 5 and 6) from the cytoplasmic storage compounds sucrose, starch and cationic compounds that retained or increased their levels of ${ }^{14} \mathrm{CO}_{2}$ following the pulse phase (Fig. 5).

Taken together the results of Figs. 4 and 6 showed that D- $g$-D- $i$-oct $1,8-\mathrm{P}_{2}$ was rapidly labelled and saturated with isotope during ${ }^{14} \mathrm{CO}_{2}$ fixation. It was delabelled on exposure to ${ }^{12} \mathrm{CO}_{2}$ during a comparative study which showed that it exhibited the same kinetics of ${ }^{14} \mathrm{C}$ loss as other cycling bisphosphate intermediates of the Calvin Pathway. It was therefore unambiguously distinguished from slow ${ }^{14} \mathrm{C}$-release carbon storage and other cytoplasmic end products of PS by the above kinetics.

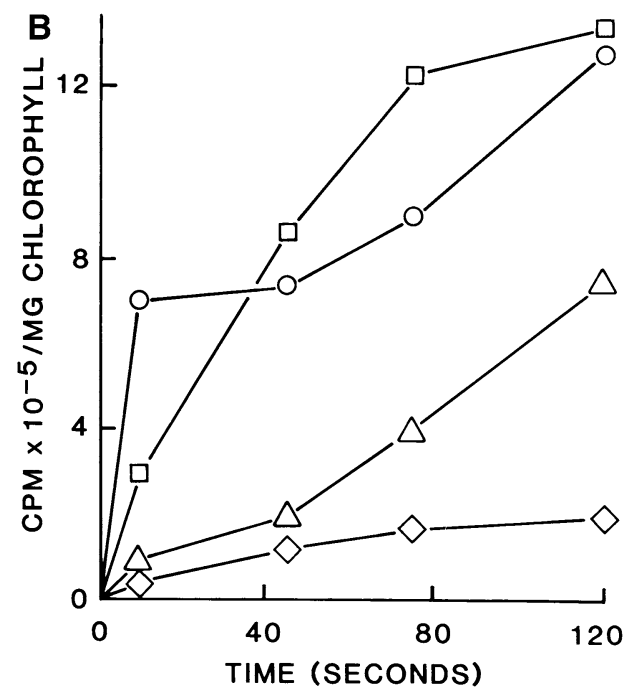

tography as described in the Materials and methods Section. The ${ }^{14}$ C-radioactivity incorporated in glucose 6-P and PGA (panel $\mathbf{A}$ ) was an order of magnitude greater than that incorporated in the sugar phosphates shown in panel B. Panel A: Total ${ }^{14} \mathrm{C}$ isotope fixed, - radioactivity incorporated in Glc 6-P, $\mathbf{-}$ and PGA, $\boldsymbol{\Delta}$. Panel B. Rib 5-P, $\square$; other pentose 5-P, $\bigcirc$; Seh 1,7- $\mathrm{P}_{2}, \Delta$ and D- $g$ D-i-oct $1,8-\mathrm{P}_{2}, \diamond$

D-glycero-D-ido-octulose $1,8-P_{2}$ in spinach chloroplasts

The above results suggested that $\mathrm{D}-\mathrm{g}$-D- $i$-oct $1,8-\mathrm{P}_{2}$ may have a chloroplast origin. In order to test this proposal, PS experiments were carried out with isolated spinach chloroplasts. If $\mathrm{D}-g$-D- $i$-oct $1,8-\mathrm{P}_{2}$ is synthesized by enzymes of the reductive $\mathrm{PP}$, it should become rapidly labelled following the metabolism of ${ }^{32} \mathrm{P}$-inorganic phosphate $\left(\mathrm{P}_{\mathrm{i}}\right)$ or ${ }^{14} \mathrm{C}$-bicarbonate. It was noted above that $\mathrm{D}$ - $g$-D- $i$-oct $1,8-\mathrm{P}_{2}$ incorporated ${ }^{14} \mathrm{C}$ isotope during PS by isolated chloroplasts in the presence of $\mathrm{NaH}^{14} \mathrm{CO}_{3}$ (see Methods). These observations were further tested using ${ }^{32} \mathrm{P}$-orthophosphate as the isotopic marker (see Methods section) in order to investigate whether D- $g$-D- $i$ oct $1,8-\mathrm{P}_{2}$ was exclusively present in the organelles and was not the result of external reactions catalysed by enzymes released from any ruptured chloroplasts. Intact chloroplasts were rapidly filtered through a layer of silicone oil (Heldt 1980) and the ${ }^{32}$ P-labelled metabolites were separated by ion-exchange chromatography (see Methods section). The unambiguous identification of the $\left[{ }^{32} \mathrm{P}\right]$-D- $g$-D- $i$-oct $1,8 \mathrm{P}_{2}$ was made by rechromatographing the recovered octulose phosphate fractions on paper using the GW3 and GW3/PBA solvents. From the known specific radioactivity of inorganic phosphate in the reaction mixture and the absolute amount of ${ }^{32} \mathrm{P}$-isotope in the purified D- $g$-D- $i$-oct $1,8-\mathrm{P}_{2}$, the concentration of the sugar phosphate in the stroma was estimated. 


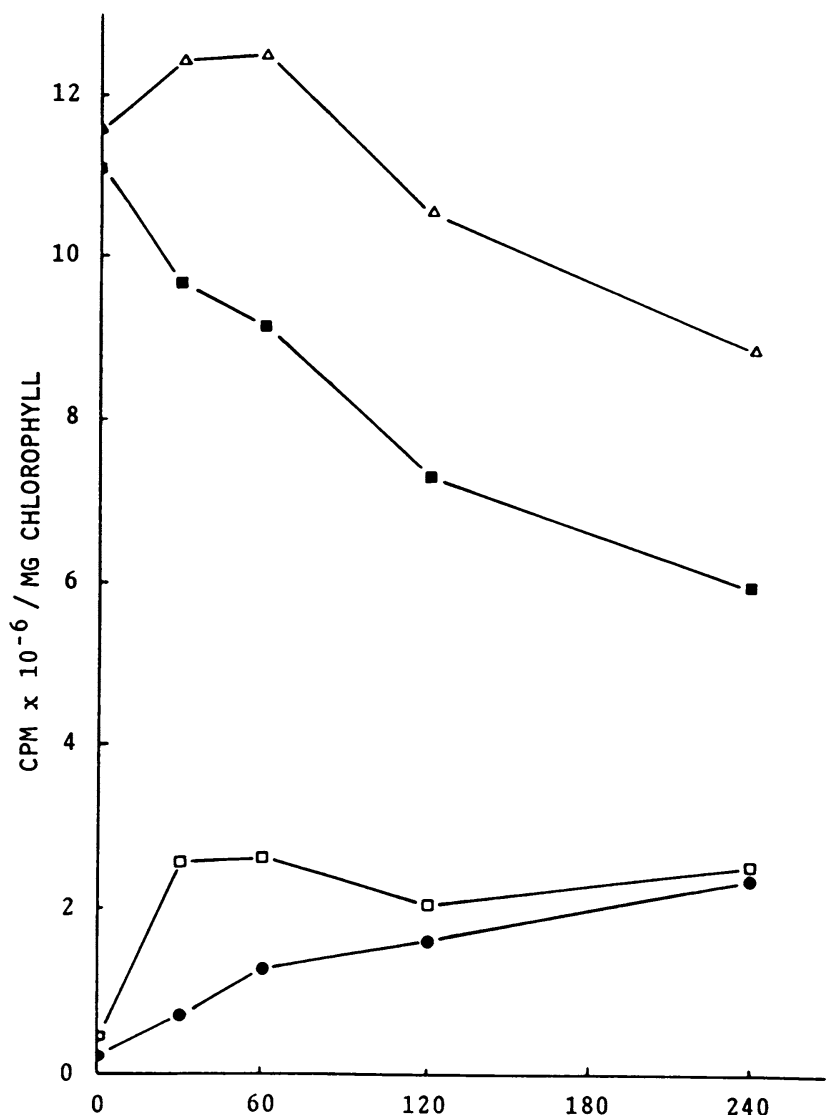

Fig. 5 Shows the results of pulse-chase experiments where spinach leaves were confined in ${ }^{14} \mathrm{CO}_{2}$ for $20 \mathrm{~s}$ (the pulse) and were then exposed to non-radioactive air (the chase). See methods. The figure shows the time-course of the partition of ${ }^{14} \mathrm{C}$ isotope into various fractional groups of compounds in spinach leaves following their exposure to the 'chase' with unlabelled $\mathrm{CO}_{2}$ for $240 \mathrm{~s}$ and illuminated to the equivalent of $50 \%$ direct sunlight. It is of note that starch and cationic compounds retained and continued to show increasing ${ }^{14} \mathrm{C}$ radioactivity while the radioactivity in the total soluble fraction and the pool of anionic compounds declined. The time-course of changes in ${ }^{14} \mathrm{C}$ radioactivity are shown for starch, $\boldsymbol{0}$; neutral and anionic compounds, $\square$; the cationic fraction, $\square$ and total soluble radioactivity, $\Delta$

Using the value of the sorbitol impermeable space of $26 \mu \mathrm{l} \mathrm{mg}^{-1} \mathrm{Chl}$ (Schafer et al. 1977), the concentration of D- $g$-D- $i$-oct $1,8-\mathrm{P}_{2}$ was estimated to be $1.3 \mathrm{nmol} \mathrm{mg}$ $\mathrm{Chl} \pm 0.50(50 \mu \mathrm{M}$, three determinations). This value is less than that measured for ido-oct in the whole leaf PS study, but is in the same concentration range as that of some other Calvin Cycle metabolites in spinach chloroplasts (Portis et al. 1977; Heldt et al. 1978, 1980; Stitt et al. 1980; Petterson and Ryde-Petterson 1988). Measurement of the amount of the altro-epimer of the octulose bisphosphate in chloroplasts was not made in this study (see the accompanying paper for the results of a mass spectrometric study of ${ }^{13} \mathrm{C}$ labelled sugar phosphates formed in spinach chloroplasts during PS).
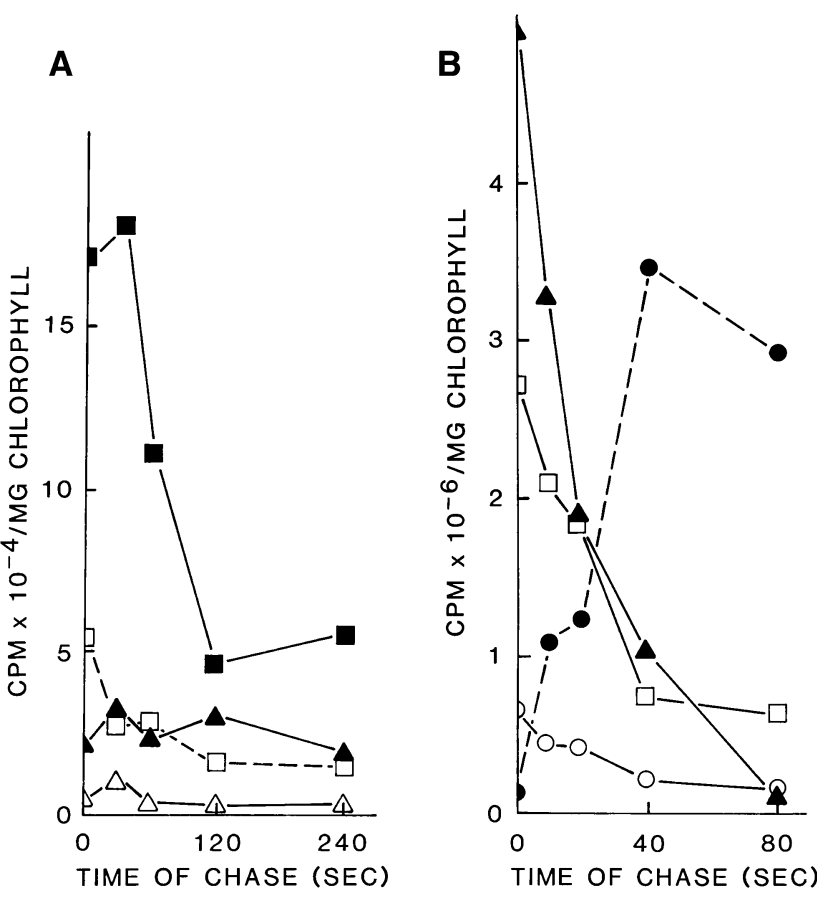

Fig. 6 Shows the change in the ${ }^{14} \mathrm{C}$-radioactivity of individual sugar phosphates and sucrose in spinach leaves during the timecourse of the 'chase' with unlabelled $\mathrm{CO}_{2}$. Sugar phosphates from leaves that had been subjected to the 'pulse-chase' experiments (See Fig. 4b results) were separated by anionexchange chromatography and individually purified by two dimensional TLC or paper chromatography. See Materials and methods for details. Panel A shows the kinetics over $240 \mathrm{~s}$ of the decline in radioactivity of Rib 5-P, $\mathbf{-}$; Fru 1,6- $\mathrm{P}_{2}, \boldsymbol{\Delta}$; DHAP, $\square$; and $\mathrm{D}$ - $g$-D- $i$-oct $1,8-\mathrm{P}_{2}, \bullet$. Panel $\mathbf{B}$ shows the time-course over $80 \mathrm{~s}$ of the decline in radioactivity of PGA, $\mathbf{\Delta}$; Glc 6-P, $\square$; Fru 6$\mathrm{P}, \mathrm{O}$; and the initial increase in radioactivity in sucrose,

A carry-through of the external medium may affect the estimation of the stromal volume as a sorbitol impermeable space and consequently the determination of the molar concentration of metabolites contained in the stroma. However, the amount of D- $g$-D-i-oct $1,8-\mathrm{P}_{2}$ in the stroma is quoted per $\mathrm{mg}$ of $\mathrm{Chl}$ and is thus independent of the volume of external medium that may be carried through silicon oil with the organelles. The results of control experiments, using ${ }^{14} \mathrm{CO}_{2}$, showed that following centrifugation, the external medium contained less than $10 \%$ of the ${ }^{14} \mathrm{C}$-labelled $\mathrm{D}$ $g$-D-i-oct $1,8-\mathrm{P}_{2}$ found in the pelleted chloroplast fraction. Thus it is concluded that $\mathrm{D}$ - $g$-D- $i$-oct $1,8-\mathrm{P}_{2}$ is probably synthesized and may react exclusively in the stromal compartment of spinach chloroplasts. Its concentration is estimated to be $50 \mu \mathrm{M}$ using the above data and the following equation:

$$
\frac{1.3 \mathrm{nmol} \text { per mg Chl } \times 1,000 \mu \mathrm{l}}{26 \mu \mathrm{l} \text { per mg Chl }}=0.05 \mathrm{nmol} \text { per } \mu \mathrm{l}(50 \mu \mathrm{M})
$$


Origin of $\mathrm{D}$ - $g$-D- $i$-oct $1,8-\mathrm{P}_{2}$ and distributions of ${ }^{14} \mathrm{C}$ isotope in a selection of sugar phosphates isolated from spinach leaves and chloroplasts assimilating ${ }^{14} \mathrm{CO}_{2}$ in photosynthesis

The most likely biosynthetic routes leading to D- $g$-D- $i$ oct phosphate formation involve catalysis by the carbon-carbon cleavage and group-transferring enzymes of sugar phosphate metabolism, namely transketolase (Eq. (3)), aldolase (Eq. (4)) and transaldolase (Eq. (5)).

Glc 6-P + Fru 6-P $\stackrel{\text { TK }}{\longleftrightarrow}$ D-g-D-i-oct 8-P + Ery 4-P

Ara 5-P + DHAP $\stackrel{\text { Ald }}{\longleftrightarrow} \mathrm{D}-g$-D $-i$-oct $1,8-\mathrm{P}_{2}$

Ara 5-P + Fru 6-P $\stackrel{\text { TA }}{\longleftrightarrow}$ D-g-D-i-oct $8-\mathrm{P}+\mathrm{GaP}$

The short-term PS experiments described in the Methods and Results sections were used to identify which of the above three enzymes may have operated for the synthesis of D- $g$-D-i-oct phosphate in spinach leaves and chloroplasts. However, it is of note that the initial hypothesis (Fig. 2) for the modified reductive PP (Clark et al. 1974; Williams et al. 1987), proposed that D- $g$-D-i-oct-8-P was formed by the reaction of (Eq. (3)) and $\mathrm{D}-g$-D- $i$-oct-1,8- $\mathrm{P}_{2}$ by the PT reaction of (Eq. (6)) (Arora et al. 1985).

D-g-D-i-oct 8-P + Seh 1,7- $\mathrm{P}_{2}$

$\stackrel{\mathrm{PT}}{\longleftrightarrow} \mathrm{D}-g$-D-i-oct $1,8-\mathrm{P}_{2}+$ Seh 7-P
Figure 2 shows that in one cycle of ${ }^{14} \mathrm{CO}_{2}$ fixation, D$g$-D- $i$-oct $1,8-\mathrm{P}_{2}$ is labelled in carbons 5 and 6 . In order to test this aspect of the mechanism of the pathway, the distributions of ${ }^{14} \mathrm{C}$ isotope into the individual carbons of Glc-6P, phosphoglyceric acid (PGA), Rib-5-P and D$g$-D-i-oct $1,8-\mathrm{P}_{2}$ were determined in samples isolated from spinach leaves and chloroplasts during light-driven PS in ${ }^{14} \mathrm{CO}_{2}$. The procedures used (see Methods section) allowed each of the carbons of Glc 6-P and PGA to be isolated for the determination of the degree of positional carbon isotopic labelling. However, only carbons $1,2,3,4$ and 8 of $\mathrm{D}$ - $g$-D- $i$-oct $1,8-\mathrm{P}_{2}$ were able to be individually isolated for ${ }^{14} \mathrm{C}$ measurement and carbons 5, 6 and 7 were collectively measured as a group (Williams et al. 1985). Only the ${ }^{14} \mathrm{C}$ isotope levels of carbons 1 and 5 of Rib-5-P were uniquely determined by the methods applied in this study, with carbons 2, 3 and 4 being estimated as a group ${ }^{14} \mathrm{C}$ measurement. The data of Table 1 show the results of these experiments using spinach leaves photosynthetically assimilating ${ }^{14} \mathrm{CO}_{2}$ for $10,45,75$ and $120 \mathrm{~s}$, respectively (see Methods section). The data of Table 2 show similar ${ }^{14} \mathrm{C}$ isotope distributions in PGA, Glc 6-P and $\mathrm{D}-\mathrm{g}$-D- $i$-oct $1,8-\mathrm{P}_{2}$ isolated from intact spinach chloroplasts after $60 \mathrm{~s}$ of PS in ${ }^{14} \mathrm{CO}_{2}$.

Degradative data for PGA, DHAP and Glc 6-P following $40 \mathrm{~s}$ of PS are also listed. Both sets of results implicate a TK-catalysed reaction (Eq. (3)) as the most likely route for the biosynthesis of D- $g$-D- $i$-oct 8 -P leading to the bisphosphate by the reaction of Eq. (6).

In order to compare the above TK path of synthesis with the ${ }^{14} \mathrm{C}$ distribution pattern that may be imposed

Table 1 Distribution of ${ }^{14} \mathrm{C}$ isotope in sugar phosphates isolated from spinach leaves following specified intervals of $\mathrm{PS}$ in ${ }^{14} \mathrm{CO}{ }_{2}^{\mathrm{a}}$

\begin{tabular}{|c|c|c|c|c|c|c|c|c|c|c|c|c|}
\hline \multirow[t]{2}{*}{ Carbon } & \multicolumn{5}{|c|}{$10 \mathrm{~s}$ of ${ }^{14} \mathrm{CO}_{2}$ fixation } & \multicolumn{3}{|l|}{$45 \mathrm{~s}$} & \multicolumn{3}{|l|}{$75 \mathrm{~s}$} & \multirow{2}{*}{$\begin{array}{l}120 \mathrm{~s} \\
\text { Glc } \\
6-\mathrm{P}\end{array}$} \\
\hline & $\begin{array}{l}\text { Glc } \\
6-P\end{array}$ & $\begin{array}{l}\mathrm{D}-g \text {-D- } i \text {-oct } \\
1,8-\mathrm{P}_{2} \\
\text { Found }\end{array}$ & Predicted & Rib 5-P & PGA & Glc 6-P & $\begin{array}{l}\mathrm{D}-g-\mathrm{D}-i-\mathrm{O} \\
1,8-\mathrm{P}_{2}\end{array}$ & & Glc 6-P & $\begin{array}{l}\mathrm{D}-g-\mathrm{D} \\
1,8-\mathrm{P}_{2}\end{array}$ & & \\
\hline 1 & 3.2 & 35.6 & (33.3) & 23.4 & 84.9 & 12.7 & 20.4 & (38.7) & 15.1 & 29.9 & $(37.3)$ & 18.5 \\
\hline 2 & 3.2 & 25.3 & (33.3) & 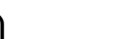 & 7.2 & 7.4 & 21.1 & $(22.6)$ & 10.3 & 30.6 & $(25.4)$ & 11.8 \\
\hline 3 & 37.2 & 39.1 & $(33.3)$ & 71.6 & 7.9 & 24.6 & 58.5 & $(38.7)$ & 22.0 & 39.5 & (37.3) & 17.2 \\
\hline 4 & 50.5 & 21.2 & $(3.1)$ & & & 38.1 & $\overline{13.1}$ & $(8.5)$ & 33.4 & 13.3 & $(12.1)$ & 25.0 \\
\hline 5 & 2.5 & & & 5.0 & & 7.0 & & & 9.1 & & & 10.7 \\
\hline 6 & 3.4 & $(60.7)$ & $(93.2)$ & & & 10.2 & 79.2 & $(79.8)$ & 10.1 & 63.7 & $(76.0)$ & 17.1 \\
\hline 7 & & & & & & & & & & & & \\
\hline 8 & & 18.1 & (3.5) & & & & 7.7 & $(11.7)$ & & 23.0 & $(11.9)$ & \\
\hline $\begin{array}{l}\% \text { recovery } \\
\text { of }{ }^{14} \mathrm{C} \text {-isotope }\end{array}$ & 88 & $91^{\mathrm{b}}$ & $76^{c}$ & 86 & 101 & 106 & $82^{\mathrm{b}}$ & $75^{c}$ & 93 & $85^{\mathrm{b}}$ & $89^{c}$ & 90 \\
\hline
\end{tabular}

a The conduct of the experiments is described in the Methods section. Sugar phosphates were isolated and purified by ion-exchange and paper chromatographic procedures. Results are mean values of duplicate degradations except for all of the compounds isolated after $10 \mathrm{~s}$ of ${ }^{14} \mathrm{CO}_{2}$ fixation, which were degraded in triplicate. ${ }^{\mathrm{b},{ }^{c} \%}{ }^{14} \mathrm{C}$ recovered in the top 3 and bottom 5 carbons of $\mathrm{D}-g$-D- $i$-oct $1,8-\mathrm{P}_{2}$ 
Table 2 Distribution of ${ }^{14} \mathrm{C}$ isotope in sugar phosphates isolated from intact spinach chloroplasts following carbon fixation by light-driven PS ${ }^{\mathrm{a}}$

\begin{tabular}{|c|c|c|c|c|c|c|c|}
\hline \multirow[t]{4}{*}{ Carbon } & \multicolumn{7}{|c|}{ Percent specific radioactivity } \\
\hline & \multicolumn{3}{|l|}{$40 \mathrm{~s}$} & \multicolumn{4}{|l|}{$60 \mathrm{~s}$} \\
\hline & \multirow[t]{2}{*}{$\overline{\mathrm{PGA}}$} & \multirow[t]{2}{*}{ DHAP } & \multirow[t]{2}{*}{$\overline{\text { Glc 6-P }}$} & \multirow[t]{2}{*}{ PGA } & \multirow[t]{2}{*}{ Glc 6-P } & \multicolumn{2}{|c|}{$\mathrm{D}-g$-D- $i$-oct $1,8-\mathrm{P}_{2}$} \\
\hline & & & & & & Found & (Theory) \\
\hline 1 & 55.1 & 59.4 & 12.5 & 46.6 & 13.6 & 56.7 & $(32.5)$ \\
\hline 2 & 18.4 & 17.2 & 7.3 & 29.2 & 14.4 & 28.4 & $(35.0)$ \\
\hline 3 & 26.5 & 23.4 & 23.0 & 24.2 & 18.3 & 14.9 & $(32.5)$ \\
\hline 4 & & & 39.1 & & 33.6 & 18.4 & $(17.0)$ \\
\hline 5 & & & 8.5 & & 9.2 & & \\
\hline 6 & & & 9.6 & & 10.9 & 64.0 & $(70.0)$ \\
\hline 7 & & & & & & & \\
\hline 8 & & & & & & 17.6 & $(13.0)$ \\
\hline$\%{ }^{14} \mathrm{C}$ recovered & 98 & 101 & 89 & 97 & 95 & $88^{\mathrm{b}}, 94^{\mathrm{c}}$ & \\
\hline
\end{tabular}

a The ${ }^{14} \mathrm{C}$-labelling experiments were carried in an oxygen electrode apparatus as described in the Methods section. Illuminated chloroplast suspensions $\left(100 \mu \mathrm{g} \mathrm{Chl} \mathrm{ml}{ }^{-1}\right.$ ) were incubated with $10 \mathrm{mM} \mathrm{NaHCO}_{3}$ until a linear rate of $\mathrm{CO}_{2}$-dependent $\mathrm{O}_{2}$ evolution was attained. One hundred $\mu \mathrm{Ci}$ of $\mathrm{NaH}^{14} \mathrm{CO}_{3}$ was added to adjust the specific radioactivity of the substrate to $5 \mu \mathrm{Ci} \mu \mathrm{mol}^{-1}$. The subsequent steps are detailed in the Methods section. The specific radioactivity of individual carbons of sugar phosphates are the mean value of triplicate determinations. ${ }^{\mathrm{b}, \mathrm{c}}$ The percent recovery of ${ }^{14} \mathrm{C}$ isotope from the top 3 and bottom 5 carbon atoms of $\mathrm{D}$ - $g$-D- $i$-oct 1,8 $\mathrm{P}_{2}$, respectively. The method for calculating the theoritical bracketed values in Tables 1 and 2 is given in the Appendix

by the reactions of Eqs. (4) and (5), catalysed by either Aldolase (ALD) or TA, theoretical distributions of ${ }^{14} \mathrm{C}$ isotope in $\mathrm{D}$ - $g$-D- $i$-oct $1,8-\mathrm{P}_{2}$ are also presented as bracketed values in Tables 1 and 2. The Appendix shows the method for calculating the theoretical values. These distributions were calculated using the experimentally measured isotope levels in Glc 6-P (Table 1) and an assumption that Fru 6-P formed in the reductive pathway is in chemical and isotopic equilibrium with Glc 6-P formed by the action of PGI. It is also assumed that the ${ }^{14} \mathrm{C}$ distributions in the mono- and bisphosphates of the D- $g$-D- $i$-octuloses of Eqs. (3) and (6) are the same.

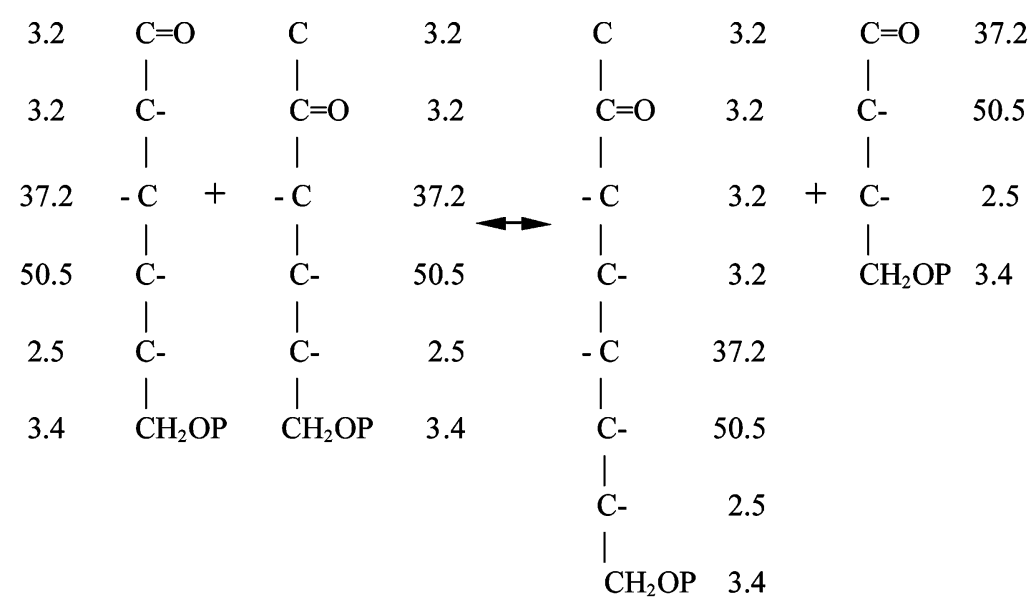

Equation (3a) shows detail of the spread of ${ }^{14} \mathrm{C}$ in each carbon of D- $g$-D- $i$-oct 8-P at $10 \mathrm{~s}$ (see data Table 1) using the mean values of triplicate estimations of ${ }^{14} \mathrm{C}$ isotope in each of the six carbons of Glc 6-P and the assumptions described above. The individual distributions measured in the top three carbons of the D- $g$-D- $i$ oct 1,8- $\mathrm{P}_{2}$ sampled at all times support the proposal that D- $g$-D- $i$-oct 8 -P in spinach leaves (Table 1 ) and chloroplasts (Table 2) may be formed by the TK reaction of Eq. (3). However, the leaf concentrations of ${ }^{14} \mathrm{C}$ in C-4 and $\mathrm{C}-8$ of $\mathrm{D}$ - $g$-D- $i$-oct $1,8-\mathrm{P}_{2}$ in the 45 -s and 75 -s samples and the 60-s chloroplast sample are greater than expected from contributions of C-1 and C-6 of hexose

$$
\text { Glu 6-P }+ \text { Fru 6-P } \stackrel{\mathrm{TK}}{\longrightarrow} \text { D-g-D-i -Oct 8-P + Ery 4-P (Eqn 3a) }
$$


phosphates to these carbons of oct 8-P formed by the reaction of Eq. (3). The level of ${ }^{14} \mathrm{C}$ in position 8 of some ido-octulose $1,8-\mathrm{P}_{2}$ samples was significant and may be the result of a second cycle of ${ }^{14} \mathrm{C}$ labelling or action by a phenomenon that was first noted by Van Sumere and Shu (1957). Their results showed an inversion of ${ }^{14} \mathrm{C}$-labelling of $\left[1-{ }^{14} \mathrm{C}\right] \mathrm{Rib}$ and production of $\left[5-{ }^{14} \mathrm{C}\right]$-Xlu via the intermediacy of ${ }^{14} \mathrm{C}$-D-arabinitol formed by D-arabinitol: $\mathrm{NAD}^{+}$4-oxidoreductase (EC 1.1.1.11). Rephosphorylation and isomerization to form the isotopically inverted aldopentose 5-P and its $\mathrm{Ald}_{x}$ catalysed exchange with $\mathrm{D}-\mathrm{g}$-D- $i$-oct $1,8-\mathrm{P}_{2}$ will specifically label position 8 . Contamination, isolation, recovery and analytical errors may be ruled out since authentically labelled D- $g$-D- $i$-oct $1,8-\mathrm{P}_{2}$ samples subject to the above procedures showed that the error in ${ }^{14} \mathrm{C}$ analysis of C-8 was $<8 \%$. However, it is important to note that neither the results of the Calvin group, the reactions of the Calvin pathway, the scheme of Fig. 2, nor the results of Table 1 show pentose phosphates labelled at positions other than carbons 1,2 and 3. The scrambling of ${ }^{14} \mathrm{C}$ into carbons 2 and 3 of 3-PGA (see Table 2 for 60 -s chloroplast data) by recycling in the path of carbon in PS is predicted to lead to some enrichment of ${ }^{14} \mathrm{C}$ isotope into positions 5 and 6 of $\mathrm{D}-g$ D- $i$-oct $1,8-\mathrm{P}_{2}$ (via the prior labelling of Fru 6-P from PGA). However, only heavily labelled $\left[1-{ }^{14} \mathrm{C}\right]$ PGA was found after $10 \mathrm{~s}$ PS in spinach leaves (Table 1). After $120 \mathrm{~s}$ of ${ }^{14} \mathrm{CO}_{2}$ exposure there was an almost uniform ${ }^{14} \mathrm{C}$ distribution in all carbons of Glc 6-P consistent with extensive recycling of the isotope in the carbon path of PS.

The results of the partial degradations of D- $g$-D- $i$-oct $1,8-\mathrm{P}_{2}$ samples do not support exclusive paths of synthesis by the reactions of Eqs. (4) and (5), since both of these reactions will very heavily label carbon 3 of octulose phosphate. Because $\left[1-{ }^{14} \mathrm{C}\right]-\mathrm{PGA}$ is the earliest and most heavily labelled intermediate detected during ${ }^{14} \mathrm{C}$ fixation in $\mathrm{C}-3$ plant $\mathrm{PS}$ and is the precursor of $\left[1-{ }^{14} \mathrm{C}\right]$-DHAP, then it follows that the aldolase reaction of Eq. (4) forms a predominantly labelled $\left[3-{ }^{14} \mathrm{C}\right]-\mathrm{D}-\mathrm{g}$-D-i-oct $1,8-\mathrm{P}_{2}$. The TA reaction of Eq. (5) uses Fru-6-P which will be most heavily, but unequally, labelled (Gibbs Effect) in positions 3 and 4 in short time-course experiments (Tables 1 and 2). Thus the transfer of the $\left[3-{ }^{14} \mathrm{C}\right]-\mathrm{DHA}-\mathrm{TA}$ moiety from $\left[3,4-{ }^{14} \mathrm{C}\right]-$ Fru $6-\mathrm{P}$ to Ara 5-P in the reaction of Eq. (5) forms $\mathrm{D}-g$-D- $i$-oct 8 -P which would have C-3 notably labelled. These predictions cannot be made in longer term experiments (much beyond $30 \mathrm{~s}$ in leaves) because of the PS-induced spread of ${ }^{14} \mathrm{C}$ label in PGA and hexose 6-P (Tables 1 and 2). The most supportive evidence for the TK reaction in the synthesis of $\mathrm{D}-g$-D- $i$ - oct phosphate is best shown in the $10 \mathrm{~s}$ fixation in spinach leaves and $60 \mathrm{~s}$ in spinach chloroplasts. It is of note that the inability of the degradative procedures (see Methods section) to provide quantitative individual ${ }^{14} \mathrm{C}$ distributions for all eight carbons of the octulose phosphates was addressed using the mass spectrometric method (MacLeod et al. 2001), the results of which are reported in the accompanying paper. The above quantitative ${ }^{14} \mathrm{C}$ - labelling of positions 5 and 6 of $\mathrm{D}-g$-D- $i$-oct $1,8-\mathrm{P}_{2}$ was qualitatively confirmed by Bartlett et al. (1989), who used twodimensional NMR Spectrometry and $60 \mathrm{~s}$ of ${ }^{13} \mathrm{CO}_{2}$ fixation by PS with intact spinach leaves (Hatch and Slack 1966) to demonstrate formation of $\left[5,6-{ }^{13} \mathrm{C}\right]-\mathrm{D}-\mathrm{g}$ $\mathrm{D}-i$-oct $1,8-\mathrm{P}_{2}$. Their results also included the first demonstration of $\operatorname{Ald}_{x}$ catalysis by showing that the $\left[5,6-{ }^{13} \mathrm{C}\right]-\mathrm{D}-g$-D- $i$-oct $1,8-\mathrm{P}_{2}$ and $\left[1,2,3-{ }^{13} \mathrm{C}\right]$-Rib 5-P, both products of PS, interconverted with $\left[4,5,6-{ }^{13} \mathrm{C}\right]-$ D- $g$-D- $a$-oct $1,8-\mathrm{P}_{2}$ and $\left[2,3-{ }^{13} \mathrm{C}\right]$-Ara 5 -P.

While the above results and the scheme of Fig. 2 support the proposal that the TK reaction leading to Oct 8-P involved Glc and Fru 6-phosphates, it should be noted that TK can accept various other substrates (Williams et al. 1987). Using the theoretical analysis method dealt with earlier in this section, it can be shown that Seh 7-P serving as a two-carbon fragment donor will give the same labelling result as that imposed by Fru 6-P. On the other hand, reaction between Glc 6-P and Xlu 5-P results in a different pattern, with $\mathrm{C}-1$ and $\mathrm{C}-2$ of the resulting $\mathrm{D}-\mathrm{g}$-D- $i$-oct 8 -P having much heavier labelling than $\mathrm{C}-3$ and thus this reaction possibility is excluded. Finally, another potential TK donor substrate is $\beta$-hydroxypyruvate. Daley and Bidwell (1977) showed that in its phosphorylated form, 3-phosphohydroxypyruvate together with phosphoserine, accounted for a substantial portion $(35 \%)$ of the ${ }^{14} \mathrm{C}$ fixed by Phaseolus vulgaris leaves during the first minute of exposure to ${ }^{14} \mathrm{CO}_{2}$ in PS. If P-hydroxypyruvate is synthesized by a carboxylation process, as the above authors imply, and is converted to hydroxypyruvate, then reaction of the latter with Glc 6-P would produce D- $g$-D- $i$-oct 8 -P labelled in the same fashion as that derived from Glc 6-P and Fru 6-P, since the distribution of ${ }^{14} \mathrm{C}$ in hydroxypyruvate resembles that in carbons 1-3 in hexose monophosphate. However, lack of data prevents our further speculation on the possible role of hydroxypyruvate as a pathof-carbon intermediate in the synthesis of octulose phosphates in spinach during PS.

This section on octulose phosphate synthesis and reactivity in PS would be incomplete without mention of the $5^{\prime}$-epimerization of octulose phosphates (Williams et al. 1978a). In such a mechanism D- $g$-D- $a$ - 
Table 3 Rates of reductive PP sequences, measured by NADH oxidation, in reactions catalysed by spinach SEP with a variety of sugar phosphates as substrates

\begin{tabular}{|c|c|c|c|}
\hline \multirow[t]{2}{*}{ Substrate } & \multirow[t]{2}{*}{ Concentration $(\mathrm{mM})$} & \multicolumn{2}{|c|}{ Rate of NADH oxidation $\left(\mu \mathrm{mol} \mathrm{h}^{-1} \mathrm{mg}^{-1} \mathrm{Chl}\right)$} \\
\hline & & Spinach $^{\mathrm{a}}$ & $\mathrm{Pea}^{\mathrm{b}}$ \\
\hline $\mathrm{Ru} 1,5-\mathrm{P}_{2}$ & 2.0 & $592 \pm 79(9)$ & 546 \\
\hline Rib 5-P & 2.0 & $743 \pm 92(10)$ & 453 \\
\hline Rib 5-P & 0.2 & $366 \pm 39(10)$ & - \\
\hline Seh 7-P & 2.0 & $183 \pm 32(12)$ & 184 \\
\hline Seh $1,7-\mathrm{P}_{2}$ & 2.0 & $76 \pm 14(10)$ & 112 \\
\hline Fru $1,6-\mathrm{P}_{2}$ & 2.0 & $10.1 \pm 2.7(10)$ & 74.1 \\
\hline Fru $1,6-\mathrm{P}_{2}$ & 1.0 & $18.2 \pm 2.9(11)$ & - \\
\hline Fru 6-P & 2.0 & $1.0^{\mathrm{c}} \pm 0.3(13)$ & 77.6 \\
\hline Fru 6-P + DHAP & $2.0 / 0.20$ & $1.8 \pm 0.4(10)$ & 142 \\
\hline Fru 6-P + PGA & $2.0 / 0.20$ & $2.9 \pm 0.4(8)$ & - \\
\hline DHAP & 2.0 & $13.1 \pm 3.1(10)$ & 53 \\
\hline DHAP & 0.20 & $5.0 \pm 1.4(11)$ & 22.6 \\
\hline Ara 5-P & 2.0 & $1.1(9)^{\mathrm{d}}$ & - \\
\hline $\mathrm{D}-g$-D- $i$-oct $1,8-\mathrm{P}_{2}$ & 2.0 & $3.7 \pm 1.7(5)$ & - \\
\hline $\mathrm{D}-g$-D- $a$-oct $1,8-\mathrm{P}_{2}$ & 2.0 & $9.3 \pm 1.5(6)$ & - \\
\hline D- $g$-D-i-oct 8 -P & 2.0 & $6.3 \pm 2.4(5)$ & - \\
\hline $\mathrm{D}-g$-D- $a$-oct 8 -P & 2.0 & $8.2 \pm 3.0$ & - \\
\hline
\end{tabular}

${ }^{a}$ Shows the results of this study. Results are mean values \pm standard deviation. The number of determinations using different batches of SEP are shown in brackets

${ }^{\mathrm{b}}$ Shows the data of Furbank and Lilley (1981) for peas

${ }^{\mathrm{c}}$ When preparations were made using sonicated spinach chloroplast suspensions and Fru 6-P as substrate, varying (non-reproducible) rates up to $5 \mu \mathrm{mol} \mathrm{h}{ }^{-1} \mathrm{mg}^{-1} \mathrm{Chl}$ were recorded

${ }^{\mathrm{d}}$ Results were variable with different SEP batches, three of the SEP preparations with Ara 5-P did not support any NADH oxidation

oct 8-P or the corresponding bisphosphate may be reversibly generated from the ido-epimeric phosphate esters. The manner of this epimerization and its significance in the proposed modification of the path of carbon in PS is treated in the last section of this Discussion.

Stromal enzyme preparation and photosynthesis

In 1981, Furbank and Lilley showed that reaction sequences of a complete photosynthetic carbon reduction pathway could be demonstrated using a SEP (see Methods section) from the chloroplasts of peas. By supplying SEP with ATP, NAD (P)H, $\mathrm{Mg}^{2+}$ and dithiothreitol (DTT) and operating at $\mathrm{pH} 8.0$, the need for light was eliminated. When SEP was provided with a small priming level of 3-PGA, there was an immediate and rapid oxidation of $\mathrm{NAD}(\mathrm{P}) \mathrm{H}$ which was spectrophotometrically monitored at $340 \mathrm{~nm}$. The amount of $\mathrm{NAD}(\mathrm{P}) \mathrm{H}$ oxidized was equated with the number of moles of 3-PGA added. During the period of rapid $\mathrm{NAD}(\mathrm{P}) \mathrm{H}$ oxidation it was shown, in parallel experiments using ${ }^{14} \mathrm{CO}_{2}$, that no carbon fixation took place. However, after this initial rapid period there followed an interval of further $\mathrm{NAD}(\mathrm{P}) \mathrm{H}$ oxidation at a slower rate, which was linear for at least $15 \mathrm{~min}$ and which was accompanied by $\mathrm{CO}_{2}$ fixation. It was as- sumed that $\mathrm{CO}_{2}$ was fixed by $\mathrm{Ru} 1,5-\mathrm{P}_{2}$ production for the ribulosebisphosphate carboxylase (EC 4.1.1.39) reaction which was supported by the test sugar-P added to the SEP reaction mixture (Table 3). Furbank and Lilley hypothesized that, in spite of a 500-fold dilution of the intact enzyme complement of chloroplasts and the loss of any attendant structural regulation, the pathway catalysed by SEP is mechanistically similar to the overall carbon fixation rate that occurs in intact organelles, although we suggest that it may not be quantitatively equivalent for all intermediates. Thus it was of interest to prepare SEP from spinach chloroplasts and investigate its comparative ability to react octulose and arabinose phosphates, and adopt its use for measurement of catalytic activity of the phosphotransferase enzyme, and the rates of the oxidative and reductive PPs (see Methods).

Determination of $\mathrm{CO}_{2}$ fixation using SEP and activity of the reductive PP with various sugar phosphate substrates

The relative capacity of SEP to fix $\mathrm{CO}_{2}$ (see Methods) depended primarily on the nature of the sugar-P primer in the incubation. In Table 3 , the rates of spinach SEP-catalysed NADH oxidation in the presence of various sugar phosphates are compared with the data 
reported by Furbank and Lilley (1981) using SEP from peas.

In general, metabolites which immediately precede the carboxylation reaction in the scheme of the reductive $\mathrm{PP}$, namely $\mathrm{Rib} 5-\mathrm{P}, \mathrm{Ru} 5-\mathrm{P}, \mathrm{Ru} 1,5-\mathrm{P}_{2}$, Seh 7-P, Seh 1,7- $\mathrm{P}_{2}$, gave very high rates of $\mathrm{CO}_{2}$ fixation as indicated by the oxidation rate of $\mathrm{NADH}$, consistent with their role in autocatalysis (Walker and Lilley 1974). However, triose, arabinose, fructose, ido- and altro-octulose phosphates exhibited low rates that were notably below the maximum rate of $\mathrm{CO}_{2}$ fixation in intact chloroplasts. Triose-P and hexose-P rates using pea SEP were also below the physiological PS rate. In particular Fru 6-P and Glc 6-P (results not shown) were very inefficient substrates for spinach SEP giving much lower values than those reported by Furbank and Lilley (Table 3) for pea preparations, results which we were able to confirm.

Lilley and Walker (1979) also reported that substrate concentrations of Fru 6-P and a reconstituted chloroplast system yielded very low rates for the enablement or support of Calvin Cycle regenerative activity by this substrate.

A number of modifications of the original procedure were introduced in an attempt to obtain higher rates of $\mathrm{CO}_{2}$ fixation with several sugar phosphates, Fru 6-P in particular. These modifications included variations in the composition of the low osmolality buffer used for the disruption of the organelles, freeze-thawing and sonication of chloroplasts, the inclusion of various components such as ThPP or glycerol in the dialysis medium and the omission of selected steps from the procedure. Notably better reproducibility, in rates of NADH oxidation, were obtained using $10 \mathrm{mM}$ HEPES buffer ( $\mathrm{pH} 8.0$ ) with $3 \mathrm{mM}$ DTT. Consequently, this method of SEP preparation was used for all reported results. The low rates obtained with hexose and the octulose phosphates were initially thought to be due to depressed activity of a key group-transferring enzyme, particularly transketolase. This was shown to be unlikely since the maximum catalytic activity of TK, as well as that of several other enzymes of the reductive $\mathrm{PP}$ in SEP, was sufficient to support rates of $\mathrm{CO}_{2}$ fixation in excess of $100 \mu \mathrm{mol} \mathrm{h}^{-1} \mathrm{mg}^{-1} \mathrm{Chl}$ (Table 4). The enzyme activities were measured between 4 and $8 \mathrm{~h}$ after chloroplasts were disrupted and are representative of their activities in SEP during progressive or serial assays of NADH oxidation.

Both the mono- and bisphosphates of D- $g$-D- $a$-oct were marginally more active substrates for the support of $\mathrm{CO}_{2}$ fixation (Table 3) than the ido-oct phosphate esters. D- $g$-D- $i$-oct $1,8-\mathrm{P}_{2}$ was least effective and has not been assigned a substrate role in a new reaction sequence for PS presented as Scheme 1 and is a conclusion of this paper. This is a curious finality to this study of the octuloses in PS since D- $g$-D- $i$-oct $1,8-\mathrm{P}_{2}$, because of its identification in the L-type PP, was the initial substrate of choice to test the hypothesis of this study

Table 4 Maximum catalytic activity of selected enzymes of the reductive PP in Spinach SEP

\begin{tabular}{|c|c|c|}
\hline \multirow[t]{2}{*}{ Enzyme } & \multicolumn{2}{|c|}{ Catalytic activity $\left(\mu \mathrm{mol} \mathrm{h}^{-1} \mathrm{mg}^{-1} \mathrm{Chl}\right)$} \\
\hline & This study & Data of Latzko and Gibbs (1969) for Spinach leaf extract \\
\hline Phosphoglycerate kinase ${ }^{a}$ & 1990 & 2423 \\
\hline Glyceraldehyde 3-phosphate dehydrogenase $\left(\mathrm{NADP}^{+}\right)^{\mathrm{b}}$ & 207 & 269 \\
\hline Transketolase $^{c}$ & $199^{\mathrm{i}} ; 103^{\mathrm{j}}$ & 194 \\
\hline Fructose-bisphosphate aldolase $^{\mathrm{d}}$ & 113 & 102 \\
\hline Fructose-bisphosphatase $^{\mathrm{e}}$ & 53 & 46 \\
\hline Sedoheptulose-bisphosphatase ${ }^{f}$ & $35^{\mathrm{k}}$ & 3.8 \\
\hline Phosphotransferase $\mathrm{g}^{\mathrm{g}}$ & $2.7^{1} ; 13.6^{\mathrm{m}}$ & - \\
\hline Transaldolase $\mathrm{h}^{\mathrm{h}}$ & 2.4 & 7.7 \\
\hline Phosphotransferase $^{\mathrm{g}}$ in Pea leaf extract & $25.3^{\mathrm{n}}$ & \\
\hline Phosphotransferase $^{g}$ in Chlorella fusca extract & $20.9^{n}$ & \\
\hline Phosphotransferase $^{\mathrm{g}}$ in Spinach leaf extract & $\mathrm{ND}^{\mathrm{n}} ; 19.3^{\mathrm{m}}$ & \\
\hline
\end{tabular}

Enzymes were assayed using the methods of: ${ }^{\mathrm{a}, \mathrm{b}}$ Latzko and Gibbs (1969); ${ }^{\mathrm{c}}$ Brin (1974); ${ }^{\mathrm{d}}$ Bergmeyer and Bernt (1974); ${ }^{\mathrm{e}}$ Latzko and Gibbs (1974); ${ }^{\mathrm{f}}$ Woodrow and Walker (1982); ${ }^{\mathrm{g}}$ Arora et al. (1985); ${ }^{\mathrm{h}}$ Brand (1974).

${ }^{i}$ Assayed using Ery 4-P and Xlu 5-P as substrates

${ }^{\mathrm{j}}$ Assayed using Rib 5-P and Xlu 5-P as substrate

${ }^{\mathrm{k}}$ Assayed using the $\mathrm{P}_{\mathrm{i}}$ liberation method

${ }^{1}$ Assayed using $\left[8-{ }^{14} \mathrm{C}\right]-\mathrm{D}-g$-D- $i$-oct $8-\mathrm{P}$ and Seh $1,7-\mathrm{P}_{2}$ as substrates

${ }^{\mathrm{m}}$ Assayed using $\left[8-{ }^{14} \mathrm{C}\right]-\mathrm{D}-\mathrm{g}$-D- $a$-oct 8 -P and Seh $1,7-\mathrm{P}_{2}$ as substrates

${ }^{n}$ Assayed using D- $g$-D- $i$-oct $1,8-\mathrm{P}_{2}$ and Seh 7-P as substrates

ND: not detected 
(see Introduction). Although $\mathrm{D}-g$-D- $i$-oct $1,8-\mathrm{P}_{2}$ has a degree of ${ }^{14} \mathrm{C}$ isotopic equilibrium with all the octulose phosphates listed in Table 3, we find no other evidence or reason to now support its inclusion in the new PS scheme. D- $g$-D- $a$-oct $1,8-\mathrm{P}_{2}$ is the most reactive octulose substrate in both reductive $\mathrm{CO}_{2}$ fixation and in its formation from the monophosphate by PT catalysis in the reductive direction of PS (see later discussion on $\mathrm{PT}$ ). However, D- $g$-D- $a$-oct $1,8-\mathrm{P}_{2}$ forms Rib $5-\mathrm{P}$ if it is cleaved by the ALD activity of SEP, so the higher $\mathrm{CO}_{2}$ fixation by $\mathrm{D}-g$-D- $a$-oct $1,8-\mathrm{P}_{2}$ (Table 3 ) may in part be attributed to some Rib 5-P release. $\mathrm{D}-g$-D- $i$-oct $8-\mathrm{P}$ is also more effective in the support of $\mathrm{CO}_{2}$ fixation (Table 3) than its bisphosphate and it is also independent, in the new PS scheme, of any need to transact the PT step at reaction XII of the new scheme (see later section). It is also noted that the Furbank and Lilley (1981) assay for $\mathrm{CO}_{2}$ fixation identified slow reacting intermediates in the reduction assay (Table 3). These intermediates may accumulate and thus be confined to a linear, non-autocatalytic (Walker and Lilley 1974) expression of PS in vitro with resultant slow synthesis of $\mathrm{Ru} 1,5-\mathrm{P}_{2}$.

Determination of the activity of the non-oxidative segment of the PP

The capacity to convert Rib 5-P to hexose 6-P is the measure of the activity of the enzymes comprising the non-oxidative segment of the PP (Williams et al. 1978b, 1987; Fig. 1). When the products of this conversion are removed by $\mathrm{NADP}^{+}$reduction, using an excess of PGI and Glc 6-PDH, the reduction rate of the pyridine nucleotide is the measure of the maximum catalytic capacity of the preparation (see Methods). The average max rate of Rib 5-P to hexose 6-P conversion by SEP was $2.29 \mu \mathrm{mol} \mathrm{h}^{-1} \mathrm{mg}^{-1} \mathrm{Chl}$ (S.D. $\pm 0.41, n=17$ ). The ability of SEP from spinach chloroplasts (Furbank and Lilley 1981) to catalyse the above process (half-life $24 \mathrm{~h}$ ) was greater than its stability in measurements of the reductive PP (half-life $6 \mathrm{~h}$ ). When SEP was prepared by the method of Kaiser and Bassham (1979), it catalysed the non-oxidative segment reactions of the PP at the rate of $3.22 \mu \mathrm{mol} \mathrm{h}{ }^{-1}$ $\mathrm{mg}^{-1} \mathrm{Chl}$ and this was enhanced, at all test times, by $30 \%$ over a 48-h stability time course by the inclusion of ThPP (0.1 mM). This suggests that TK may have been susceptible to inactivation by the assay system (Murphy and Walker 1982). However, comparison of these data with the above results for the reductive PP show that the maximum catalytic capacity of the nonoxidative segment of PP in SEP, using Rib 5-P as substrate, is only $0.6 \%$ of Rib 5-P carboxylating activity in the reductive PP (Table 3 ). The above finding thus discounts the possibility that the complete network of the PP (Fig. 1) in SEP can make any significant overlapping contribution to the flux of the reductive PP of PS.

\section{Phosphotransferase activity}

The proposed alternative mechanism for the regenerative phase of the path of carbon in PS (Fig. 2) presents a number of features in common with the L-type PP in animal tissues (Fig. 1) (Williams et al. 1978a, 1987; Williams 1980). In particular, both pathways require the participation of a specific phosphotransferase, PT (see Methods). The presence and an excess of PT activity to support the maximum flux of Rib 5-P conversion to hexose and triose-P in vitro was reported for a number of animal and plant tissues (Arora et al. 1985). PT catalysed the reaction of Eq. (6), using the same rat liver enzyme catalyst that generated results used for the initial hypothesis of the classical (F-type) PP (Horecker et al. 1954; Horecker 2002; Williams et al. 1987). PT was also detected in French Press extracts of green algae (Chlorella fusca) and enzyme extracts of pea leaf (Arora et al. 1985) (see Table 4). The PT enzyme has not previously been investigated for any putative role in the metabolism of plants.

The detection of ${ }^{13} \mathrm{C}$ and ${ }^{14} \mathrm{C}$-labelled $\mathrm{D}$ - $g$-D- $i$-oct $1,8-\mathrm{P}_{2}$ in spinach leaves (Bartlett et al. 1989) and isolated chloroplasts following short periods of ${ }^{14} \mathrm{CO}_{2}$ assimilation (this paper), raised the question of the origin of this bisphosphate compound. The reaction of Eq. (3) shows the formation of D- $g$-D- $i$-oct 8 -P and the data reported here examine the activity and mechanism of phosphate donor and transfer for the formation of $\mathrm{D}-g$-D- $i$-oct $1,8-\mathrm{P}_{2}$. In particular the phosphotransferase proposed by Williams and Clark (1971), Clark et al. (1974) and Arora et al. (1985) is featured. The L-type PP (Fig. 1) and the hypothesized path of carbon in PS (Fig. 2) proposed a phosphotransferase which catalysed a reversible phosphate transfer between octulose and sedoheptulose phosphates (Eq. (6)). The investigations reported on this reaction were made using spinach leaf extracts and SEP preparations from spinach chloroplasts. PT activity was not detected using either spinach leaf extract or SEP to catalyse the reaction of Eq. (6) when the measurements were performed in the oxidative direction of D- $g$-D- $i$-oct 8-P formation (Fig. 2). A study of SEP-catalysed phosphate transfer from Seh $1,7-\mathrm{P}_{2}$ to $\left[8-{ }^{14} \mathrm{C}\right]-\mathrm{D}-g$-D- $i$-oct 8 -P (Eq. (1) in the reductive direction of the PS pathway), using the radiochromatographic stop assay procedure (see Methods), showed 
PT activity was $2.7 \mu \mathrm{mol} \mathrm{h}^{-1} \mathrm{mg}^{-1}$ Chl (S.D. \pm 0.80 ; $n=7$ ) (Table 4). This value exceeded the maximum rate of SEP-catalysed conversion of Rib 5-P to hexose phosphates but was only $16 \%$ of the chloroplast $\mathrm{CO}_{2}$ fixation rate required by the PT reaction step (See New Scheme) and $15 \%$ of the degree of carboxylation required for the ab initio synthesis of octulose (120/8) by PS. ${ }^{14} \mathrm{C}$-labelled $\mathrm{D}$ - $g$-D- $a$-oct 8 -P was a more effective substrate in this PT assay with activity of $13.6 \mu \mathrm{mol} \mathrm{h}^{-1} \mathrm{mg}^{-1} \quad$ Chl $\quad$ (P.E. $\pm 3.0 ; \quad n=4 ; \quad$ see Table 4), which is $80 \%$ of the required chloroplast $\mathrm{CO}_{2}$ fixation rate at the PT step of the revised RPP scheme and $91 \%$ of the activity necessary for octulose formation. Significant PT activity was found in spinach leaf extract (19.3 $\mu \mathrm{mol} \mathrm{h}^{-1} \mathrm{mg}^{-1} \mathrm{Chl}$, see Table 4) using the above radiochromatographic method and the $\left[8-{ }^{14} \mathrm{C}\right]-$ D- $g$-D- $a$-oct 8-P substrate (Eq. (2)). No activity was detected in the leaf extract using $\mathrm{D}-g$-D- $i$-oct $1,8-\mathrm{P}_{2}$ and oxidative direction assays (see Table 4). However, it is not concluded that positive PT measurement in the reductive PS mode is evidence for an exclusive unidirectional flux mechanism. Rather the failure in the application of the oxidative-mode methods (Arora et al. 1985) is attributed inter alia to subversively high levels of $\mathrm{Mg}^{+}$and DTT in SEP.

A test of the absolute specificity of the PT reaction was made using $\left[1-{ }^{32} \mathrm{P}\right]-$ Seh $1,7-\mathrm{P}_{2}$ substrate and $\mathrm{D}-g$-D$i$-oct 8-P. The reaction was carried out using SEP and exactly the same conditions as the above radiochromatographic stop assay. All ${ }^{32} \mathrm{P}$-labelled products of the reaction were resolved using formate ion-exchange chromatography (see Methods) and their radioactivity measured. ${ }^{32} \mathrm{P}-\mathrm{D}-g$-D- $i$-oct $1,8-\mathrm{P}_{2}$, which coincided with the elution peak of the authentic compound, was recovered and its identity further confirmed by rechromatography with DEAE-Sephadex A25 (borate form) (Kapuscinski et al. 1985). Aldolase cleavage of the purified Oct $1,8-\mathrm{P}_{2}$ and isolation of ${ }^{32} \mathrm{P}-\mathrm{DHAP}$ using short column $\left(0.9 \times 15 \mathrm{~cm}^{2}\right)$ formate ion-exchange chromatography, showed that $>90 \%$ of the incorporated ${ }^{32} \mathrm{P}$ was in this compound. The results of this experiment indicated that qualitatively SEP has enzymatic activity capable of specifically phosphorylating D- $g$-D- $i$-oct 8 -P at position 1 using Seh $1,7-\mathrm{P}_{2}$ as the phosphate donor. There was also an extensive $12 \%$ conversion of the $\left[1-{ }^{32} \mathrm{P}\right]-\mathrm{Seh} 1,7-\mathrm{P}_{2}$ to ${ }^{32} \mathrm{P}_{\mathrm{i}}$ and $30 \%$ formation of $\left[{ }^{32} \mathrm{P}\right]-$ Fru $1,6-\mathrm{P}_{2}$. Only $25 \%$ of the $\left[1-{ }^{32} \mathrm{P}\right]-$ Seh 1,7- $\mathrm{P}_{2}$ substrate remained after $30 \mathrm{~min}$ of reaction time. When $10 \mathrm{mM} \mathrm{Mg}^{2+}$ and $10 \mathrm{mM}$ DTT were included in the above reaction mixture, $93 \%$ of the ${ }^{32} \mathrm{P}$ label of $\left[1-{ }^{32} \mathrm{P}\right]-$ Seh $1,7-\mathrm{P}_{2}$ was converted to ${ }^{32} \mathrm{P}_{i}$ and only $0.08 \%$ to the isotopically labelled $\mathrm{D}-g$-D- $i$-oct 1 , $8-\mathrm{P}_{2}$. It is suggested that high concentrations of $\mathrm{Mg}^{2+}$ in
SEP may have activated chloroplastic bisphosphatases and account in part or completely for an inability to demonstrate significantly higher activities of PT. Inclusion of DTT and the endogenous levels of aldolase in SEP and spinach leaf extracts possibly acted to further diminish the full expression of the activity of the PT enzyme. Hence the minimum qualification for the measurements of the crude activity of PT.

During the conduct of the above investigations and measurements of PT activity, the various SEP preparations were also used to test the possibility that other intermediary compounds and enzymes may act to phosphorylate D- $g$-D- $i$-oct 8 -P. Among the test substrates were $\left[\gamma_{-}{ }^{32} \mathrm{P}\right]$-ATP, 1,3-diphosphoglycerate, inorganic pyrophosphate, Fru $1,6-\mathrm{P}_{2}$ and $\mathrm{Ru} 1,5-\mathrm{P}_{2}$. The following purified enzymes and enzyme preparations were also investigated; PFK from rabbit muscle, phosphoribulokinase (EC 2.7.1.19) from spinach, the endogenous kinases of SEP using $\left[\gamma^{32} \mathrm{P}\right]$-ATP as substrate and sedoheptulose 1,7-bisphosphatase. In summary, none of these enzymes or substrates was effective except for muscle PFK which catalysed the formation of $\left[1-{ }^{32} \mathrm{P}\right]-\mathrm{D}-g$-D- $i$-oct $1,8-\mathrm{P}_{2}$ from the reaction of $\left[\gamma^{-32} \mathrm{P}\right]$-ATP and D- $g$-D- $i$-oct 8 -P. Notwithstanding this, when SEP was used to catalyse the same reaction only a miniscule rate of labelled D- $g$-D- $i$-oct $1,8-\mathrm{P}_{2}$ formation was measured $\left(0.3 \mu \mathrm{mol} \mathrm{h}{ }^{-1} \mathrm{mg}^{-1}\right.$ Chl). PFK accepts Fru 6-P and Seh 7-P as substrates (Karadsheh et al. 1973) and on the basis of the above finding $\mathrm{D}-g$-D- $i$-oct 8 -P may be added to the list. However, the maximum catalytic activity of PFK in spinach chloroplasts is only $2.5 \mu \mathrm{mol} \mathrm{h}{ }^{-1} \mathrm{mg}^{-1} \mathrm{Chl}$ (Kelly and Latzko 1977) and it is therefore unlikely to be a significant contributor to $\mathrm{D}-g$-D- $i$-oct $1,8-\mathrm{P}_{2}$ formation in RPP reactions in PS. The results of this section (Table 4) showed that minimum estimates of PT were compromised when SEP is the source of activity. The results also showed that D- $g$-D- $a$-oct phosphate was the most active substrate and that PT may be the ratelimiting enzyme for octulose involvement in path of carbon reactions. This limitation in minimum estimates of PT activity in SEP (Table 3) may account for altrooctuloses being restricted to the support of only $11 \%$ of the rate of $\mathrm{CO}_{2}$ fixation by intact spinach chloroplasts and/or $80 \%$ of the maximum $\mathrm{CO}_{2}$ rate required at the PT reaction step (See later discussion of the new reactions in Scheme 1).

Arabinose 5-phosphate reactions with spinach stromal enzyme preparation

In the L-type PP (Fig. 1), the prior formation of Ara $5-\mathrm{P}$, and its use by aldolase is the key step for the 
New Reaction Sequence For The RPP and Required Rate for Each Reaction

Ribulosebisphosphate Carboxylase ( $100^{\mathrm{a}}$ )

6 Ribulose 1,5- $\mathrm{P}_{2}+6 \mathrm{CO}_{2}+6 \mathrm{H}_{2} \mathrm{O} \rightarrow 12$ Glycerate 3-P

Phosphoglycerate Kinase ( 200 )

12 Glycerate $3-\mathrm{P}+12$ ATP $\rightarrow 12$ Glycerate $1,3-\mathrm{P}_{2}+12$ ADP

D-Glyceraldehyde 3-P Dehydrogenase (NADP specific) ( 200 )

12 Glycerate $1,3-\mathrm{P}_{2}+12 \mathrm{NADPH}+12 \mathrm{H}^{+} \rightarrow 12$ Glyceraldehyde $3-\mathrm{P}+12 \mathrm{NADP}^{+}+12 \mathrm{P}_{\mathrm{i}}$ ( III ) Triosephosphate Isomerase ( 58 )

7 Glyceraldehyde 3-P $\leftrightarrow 7$ Dihydroxyacetone -P

Fructose 1,6- Bisphosphate Aldolase (41)

5 Glyceraldehyde 3-P +5 Dihydroxyacetone-P $\leftrightarrow 5$ Fructose 1,6- $\mathrm{P}_{2}$ Fructose 1,6- Bisphosphatase ( 41 )

5 Fructose $1,6-\mathrm{P}_{2}+5 \mathrm{H}_{2} \mathrm{O} \rightarrow 5$ Fructose 6-P $+5 \mathrm{P}_{\mathrm{i}}$ Phosphoglucose Isomerase ( 17 )

2 Fructose 6-P $\leftrightarrow 2$ Glucose 6-P

Transketolase ( 17 )

2 Fructose 6-P +2 Glucose 6-P $\leftrightarrow 2$ Erythrose 4-P + 2 D-g-D-i-oct 8-P

Transaldolase (Exchange $)\left(17^{\mathrm{b}}\right)$

2 D- $g$-D- - -oct 8-P +2 Ribose 5-P $\longleftrightarrow 2$ Arabinose 5-P + 2 D- $g$-D- $a$-oct 8-P

Arabinosephosphate 2'-epimerase (17)

2 Arabinose 5-P 2 Ribose 5-P

Aldolase (17)

2 Erythrose 4-P + 2 Dihydroxyacetone-P $\leftrightarrow 2$ Seh 1,7- $\mathrm{P}_{2}$ Phosphotransferase (17)

2 Seh 1,7- $\mathrm{P}_{2}+2$ D- $g$-D- $a$-oct $8-\mathrm{P} \longleftrightarrow 2$ Seh 7-P +2 D- $g$-D- $a$-oct $1,8 \mathrm{P}_{2}$

Aldolase (17)

2 D- $g$-D- $a$-oct 1,8-P $\leftrightarrow 2$ Ribose 5-P +2 Dihydroxyacetone - P Transketolase ( 17 )

( XIII )

2 Seh 7-P +2 Glyceraldehyde 3-P $\leftrightarrow 2$ Ribose 5-P +2 Xylulose 5-P Phosphoribose isomerase ( 17 )

4 Ribose 5-P 44 Ribulose 5-P

Phosphoketopentose epimerase (17)

2 Xylulose 5-P $\leftrightarrow 2$ Ribulose 5-P

Phosphoribulokinase (100)

SUM REACTION:

6 Ribulose 5-P + 6 ATP $\rightarrow 6$ Ribulose 1,5- $\mathrm{P}_{2}+6$ ADP

( XVII )

$6 \mathrm{CO}_{2}+18 \mathrm{ATP}+12 \mathrm{NADPH}+12 \mathrm{H}^{+}+5 \mathrm{H}_{2} \mathrm{O} \rightarrow$ Fructose $6-\mathrm{P}+18 \mathrm{ADP}+12 \mathrm{NADP}^{+}+17 \mathrm{P}_{\mathrm{i}} \quad(\mathrm{XVIII})$

a The rates (shown at each enzyme title) are expressed in $\mu$ moles $\mathrm{h}^{-1} \mathrm{mg}^{-1} \mathrm{Chl}$. The rate required is calculated for

$\mathrm{CO}_{2}$ fixation of 100 and the assumption that the Sum Reaction is that shown in (XVIII). The $\mathrm{V}_{\text {MAX }}$ of all the enzymes, except PT exceeds the rates required (See Robinson and Walker 1981) and the data of Table 4.

b Only catalytic amounts of Rib 5-P and Ara 5-P (provided by the steady-state concentrations of these pentose phosphates in the stroma of the chloroplasts) are required for the Exchange transacted in Reaction (IX).

formation of $\mathrm{D}-g$-D- $i$-oct $1,8-\mathrm{P}_{2}$. In contrast, the hypothetical mode of $\mathrm{D}-g$-D- $i$-oct 8 -P synthesis and reaction in the PS scheme of Fig. 2 results in the later formation of Ara 5-P and its contribution to Rib 5-P (via Ru 5-P). Thus it was anticipated that Ara 5-P by its initial assignment of an intermediary role in the flux of the pathway of Fig. 2, should support $\mathrm{CO}_{2}$ fixation in the SEP assay system. The result (Table 3 ) of the test of this proposition was negative. Arabinose 5-P, as a single test substrate, had negligible ability to support $\mathrm{CO}_{2}$ fixation in SEP-catalysed reductive PP reactions in PS. A second question raised by the hypothetical scheme of Fig. 2 is whether SEP is able to catalyse Ara 5-P dissimilation and interconvert it into other intermediates of either the Calvin Pathway or octulose phosphates. SEP catalysed the incorporation of radio- 


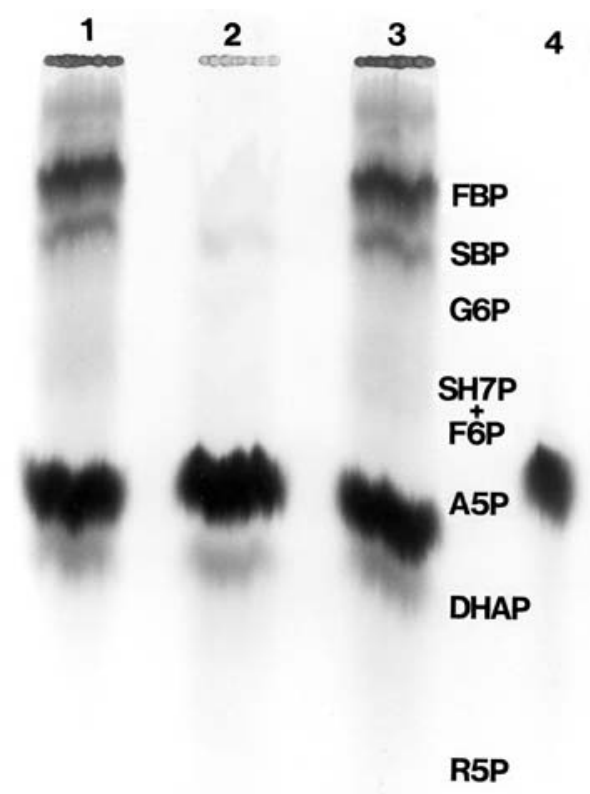

Fig. 7 Radioautogram showing the spinach SEP-catalysed conversion of $\left[\mathrm{U}_{-}{ }^{14} \mathrm{C}\right]$-Ara $5-\mathrm{P}$, in the presence of a nine-fold excess of unlabelled Rib 5-P, to other radioactively labelled sugar phosphates. [ $\mathrm{U}_{-}^{14} \mathrm{C}$ ]-Ara 5-P and Rib 5-P were incubated for $1 \mathrm{~h}$ with spinach SEP as detailed in Materials and methods. The products of the reaction were separated by descending paper chromatography using the GW3-PBA solvent. Lanes 1 and 3 of the chromatogram show the mixture of ${ }^{14} \mathrm{C}$-labelled sugar phosphates formed from Ara 5-P dissimilation. Lane 2 shows the radioautograph of products in the absence of Rib 5-P. Lane 4 shows an absence of product formation when boiled SEP was used. The identity, by visualization, of the ${ }^{14} \mathrm{C}$-labelled sugar phosphates at Lanes 1 and 3 was established by comparison with the positions (not shown in Fig. 7) of the following sugar phosphate marker standards that accompanied the four lanes of the chromatogram, Fru 1, 6- $\mathrm{P}_{2}$ (FBP), Seh 1,7- $\mathrm{P}_{2}$, Seh-7-P, Glc 6-P, Fru 6-P, Ara 5-P, DHAP, Ru 5-P, Xlu 5-P. The one-dimensional chromatography system used does not permit the identification of octulose phosphates (see Kapuscinski et al. 1985 for a list of $\mathrm{R}_{\mathrm{p}-\mathrm{i}}$ values for some of the above sugar phosphates resolved by the GW3-PBA solvent). The visualization and tentative identification of the labelled products was distinct except for the band running just ahead of Ara 5-P which may have involved ketopentose 5-phosphates and DHAP

activity from $\left[\mathrm{U}_{-}{ }^{14} \mathrm{C}\right]$-Ara $5-\mathrm{P}$ into the carbons of the following sugar phosphate intermediates of the reductive PP; triose-P, ketopentose 5-phosphates, hexose and heptulose mono- and bisphosphates (Fig. 7).

However, ${ }^{14} \mathrm{C}$-incorporation into these products only occurred in the presence of an excess (nine-fold) of unlabelled Rib 5-P. The process only faintly labelled Rib 5-P. When $2 \mathrm{mM}\left[\mathrm{U}_{-}{ }^{14} \mathrm{C}\right]$-Ara 5 -P was the sole substrate, its conversion to other identified ${ }^{14} \mathrm{C}$-labelled sugar phosphates was only $2 \%$ and there was clear incorporation into an unresolved band of phosphorylated compounds with an $R_{\mathrm{f}}$ value coincident with the ketopentose phosphates and also close to DHAP
(Fig. 7). It was imperative to ensure that ${ }^{14} \mathrm{C}$-incorporation into the sugar phosphates was not the result of non-enzymatic conversions occurring during sample processing. This possibility was eliminated on the basis of several control experiments which included different ways of terminating the reaction (boiling and perchloric acid treatment) and incubations with SEP boiled before the addition of [U- $\left.{ }^{14} \mathrm{C}\right]$-Ara 5-P.

When the incubations were carried out with SEP at $\mathrm{pH} 8.0$ in the presence of $10 \mathrm{mM} \mathrm{MgCl}_{2}$ and $10 \mathrm{mM}$ DTT (conditions favouring activation of some key regulatory enzymes of the reductive $\mathrm{PP}$ ), there was no incorporation of ${ }^{14} \mathrm{C}$ isotope from $\left[\mathrm{U}^{14} \mathrm{C}\right]$-Ara 5 -P (and excess Rib 5-P) into any other metabolites. Since the experiments used SEP that had provided approx $10 \%{ }^{14} \mathrm{C}$ incorporation from $\left[\mathrm{U}_{-}{ }^{14} \mathrm{C}\right]$-Ara $5-\mathrm{P}$ (in the presence of a nine-fold excess of Rib 5-P) into hexose 6-P and by visual judgement of the chromatogram, incorporations into Triose-P, $\mathrm{Ru} 5-\mathrm{P}$, Fru- and Seh-bisphosphates, it was concluded that $\mathrm{Mg}^{2+}$ or the reductant may be inhibitory. These latter observations were not pursued further. The above is the first report of Ara 5-P reaction in a chloroplast preparation.

Arabinose 5-P is a competitive inhibitor of TAcatalysed reactions, with a $K_{\mathrm{i}}$ of $70 \mu \mathrm{M}$ (Williams et al. 1978a). D-manno-Heptulose 7-P, a product of TK catalysis using a ketosugar-P donor and Ara 5-P, is a competitive inhibitor of TK-catalysed reactions involving Ery 4-P (Arora 1984). Moreover, in all animal and neoplastic tissues investigated (Williams et al. 1987), Ara 5-P acted as a powerful competitive inhibitor $\left(K_{\mathrm{i}}: 40 \mu \mathrm{M}\right.$, Arora 1984) when the tissue enzyme preparations converted Rib 5-P to hexose and triose phosphates using standard assay conditions for the non-oxidative PP (Methods section). Thus it was reasoned that enzyme inhibition may be responsible for the failure to find uncontentious evidence that Ara 5-P is a utilized substrate in reactions catalysed by spinach SEP. This proposition was tested with SEP using [Ara 5-P]:[Rib 5-P] ratios ranging from 0.25 to 1.0. Some inhibition was found but it was notably less than that uniformly encountered with animal and neoplastic tissue enzyme preparations. Even a 1:1 mixture of Ara 5-P and Rib 5-P with SEP exhibited $75 \%$ of the control rate measured with Rib 5-P alone. This small degree of inhibition is therefore not an explanation for the inability of SEP to catalyse Ara 5-P as a substrate in carboxylation reactions. In experiments that involved incubation of SEP with unlabelled Ara 5-P and $\mathrm{NaH}^{14} \mathrm{CO}_{3}$, slow ${ }^{14} \mathrm{C}$ fixation occurred (1 $\mu \mathrm{mol} \mathrm{h}^{-1} \mathrm{mg}^{-1}$ Chl.).

Replacement of Ara 5-P with Rib 5-P resulted in a rapid rate of formation of acid stable ${ }^{14} \mathrm{C}$-labelled 
product consistent with the peak activity of Rib 5-P in reductive PP reactions, as shown by the data of Table 3. Moreover, using the polarographic method for measuring $\mathrm{CO}_{2}$-dependent $\mathrm{O}_{2}$ evolution (Methods section) and intact spinach chloroplasts, it was found that the inclusion of $0.2 \mathrm{mM}$ Rib 5-P stimulated the rate of $\mathrm{O}_{2}$ evolution by $27 \%$ and the same concentration of Ara 5-P stimulated the rate by $7.5 \%$. Schafer et al. (1977) found that free Ara and Rib were transported into intact chloroplasts at equal rates and the above data suggest that spinach chloroplasts may be differentially permeable to the phosphates, with Rib 5$\mathrm{P}$ being 3.6 times more accessible and effective than Ara 5-P. There is also controversy about the substrate role of D-Ara 5-P in higher organisms (a brief statement of its intermediary metabolic history is given in Williams et al. 1987). Interconversion of Ara 5-P with other pentose phosphates (via isomerization to $\mathrm{Ru} 5-\mathrm{P}$ ) by microorganisms has been known for a considerable time (Volk 1960) but the direct evidence for such a process in rat liver was first demonstrated by Bleakley et al. (1984). The enzyme equilibrating Ara 5-P with other pentose phosphates was originally proposed to be of the epimerase type (Williams and Clark 1971), however, work with pig liver suggested that utilization and conversion of Ara 5-P to other metabolites may proceed via $\mathrm{Ru}$ 5-P (Williams unpublished results). The essence of the controversy concerning the metabolism of Ara 5-P is not so much its formation and presence in plant and other tissues but its comparatively low rate of substrate utilization by tissue enzyme preparations in vitro, usually only at $2-10 \%$ of the rate of Rib 5-P dissimilation. This is the case reported here where SEP catalysed utilization of Ara 5-P was extremely low. This controversy was settled when Bartlett et al. (1989) and Flanagan et al. (1993) demonstrated the role that catalytic quantities of Ara 5-P and Rib 5-P were able to play in TA and ALD exchange reactions. These exchange reactions affected 5 -epimerase interconversions of D- $g$-D- $i$-oct 8 -P and D$g$-D- $a$-oct 8 -P and their bisphosphates. It was shown that Ara 5-P was reversibly exchanged into positions 48 of the octulose phosphates with exchange rates that were greater than the mass transfer flux rates catalysed by the maximum catalytic capacities of each of the group transferring enzymes TA and ALD acting in the reactions of the following equations.

$$
\begin{aligned}
& \text { D- } g \text {-D- } i \text {-oct } 8-\mathrm{P}+\text { Rib 5-P } \stackrel{\text { TA-Exchange }}{\longleftrightarrow} \text { Ara 5-P+ D- } g \\
& \text {-D- } a \text {-oct } 8-\mathrm{P}
\end{aligned}
$$

$$
\begin{aligned}
& \text { Ara 5-P } \text { Arabinose 5-phosphate ketol-isomerase }^{\longleftrightarrow} \mathrm{Ru} 5 \text {-P } \\
& \text { Ru 5-P } \stackrel{\text { Ribose 5-phosphate isomerase }}{\longleftrightarrow} \text { Rib 5-P }
\end{aligned}
$$

Sum Reaction: $\mathrm{D}-g$-D- $i$-oct 8 -P $\longleftrightarrow \mathrm{D}-g$-D- $a$-oct 8 -P

$$
\begin{aligned}
& \text { D- } g \text {-D- } i \text {-oct } 1,8-\mathrm{P}_{2}+\text { Rib 5-P } \stackrel{\text { Ald-Exchange }}{\longleftrightarrow} \mathrm{D}-g \\
& \text {-D- } a \text {-oct } 1,8-\mathrm{P}_{2}+\text { Ara 5-P }
\end{aligned}
$$

The roles of Eqs. (7) and (8) are shown at reactions IX and $X$ in the following new reaction sequence (Scheme 1) for the path of carbon in PS. Taken together these reactions catalyse the epimerization of the ido- and altro-octulose monophosphates. Equation (11) shows the interconversion of ido- and altro-octulose bisphosphates by the aldolase exchange reaction (Bartlett et al. 1989; Flanagan et al. 1993). It is proposed that the reaction of 11 assists in the prevention of an accumulation of the much slower reacting $\mathrm{D}-g-\mathrm{D}-$ $i$-oct $1,8-\mathrm{P}_{2}$ by rapidly channelling its carbon into the more reactive $5^{\prime}$-epimeric form, D- $g$-D- $a$-oct $1,8-\mathrm{P}_{2}$ (see XII and XIII in Scheme I involving octulose phosphates in PS). The experimental results of this paper and the reactions of IX, XII and XIII in the reaction scheme suggest that D- $g$-D- $a$-oct mono- and bisphosphates become the reactive forms of ido-octulose phosphates by the reactions of (7) and (11) using Rib 5-P and Ara 5-P as cycling catalytic co-factors in reactions catalysed by $\mathrm{TA}_{\mathrm{x}}$ and $\mathrm{Ald}_{\mathrm{x}}$. We now discount any role for D-glycero-D-ido-octulose $1,8-\mathrm{P}_{2}$ as was initially proposed for the Fig. 2 hypothesis. The revised scheme only differs significantly from Fig. 2 at reaction IX, where 5 '-epimerization of $\mathrm{D}-g$-D- $i$-oct 8 -P to D- $g$-D$a$-oct 8 -P occurs. From that point ido-octulose phosphates are omitted from any further involvement in the completion of the cycle. Using PT activity data with D$g$-D- $a$-oct 8 -P as substrate (Table 4 ), it is calculated that the revised sequence may make a contribution that ranges from $11 \%(13.6 / 120)$, based on the rate of $\mathrm{CO}_{2}$ fixation $\left(120 \mu \mathrm{mol} \mathrm{h}^{-1} \mathrm{mg}^{-1} \mathrm{Chl}\right)$ in intact chloroplasts, to a maximum of $80 \%(13.6 / 17)$ based on the required $\mathrm{CO}_{2}$ fixation rate $\left(17 \mu \mathrm{mol} \mathrm{h}^{-1} \mathrm{mg}^{-1} \mathrm{Chl}\right)$ at the PT step (reaction XIII) of Scheme 1 for the RPP.

Finally, it is concluded that metabolic function has directed a distinct and confining intermediary metabolism on ido- and altro-octulose phosphates. In the L-type PP (Fig. 1) selection of D-glycero-D-ido-octulose phosphates realised the formation of the metabolically active products Fru 6-P and Glc 6-P. D-glycero-D-altroOctulose phosphates in the pathway of Fig. 1 will only 
lead to the formation of Fru 6-P and the dead-end product D-allose 6-P. In Scheme 1 formulated here, the formation of D- $g$-D- $a$-oct $1,8-\mathrm{P}_{2}$ leads to the production of Rib 5-P, the most active intermediate for the support of $\mathrm{CO}_{2}$ fixation (Table 3). Formation and further utilization of $\mathrm{D}-g$-D- $i$-oct $1,8-\mathrm{P}_{2}$ by the reaction scheme would produce stoichiometric amounts of Ara 5-P which, as a metabolic product, has no ability to fix $\mathrm{CO}_{2}$ (Table3).

Acknowledgements The work was supported by grants to J.F.W. from the Australian Research Grants Committee and The Faculties Research Fund of The Australian National University. Technical assistance by K.K. Arora, I.L. Flanigan, M.K. Kapuscinski and Elisabeth Owen is acknowledged.

\section{Appendix}

The method used to calculate the predicted labelling patterns of D- $g$-D- $i$-oct phosphates formed by the reactions of Eqs. (3) and (6) is shown. The synthesis of $\mathrm{D}-g$-D- $i$-oct 8 -P is proposed to proceed via the TKmediated reaction of Glc 6-P and Fru 6-P (Eq. (3a)). It is assumed that the two hexose 6-phosphates are in chemical and isotopic equilibrium and therefore have the same distributions of ${ }^{14} \mathrm{C}$ isotope. As an example, the method illustrates the application of the analytical data for the 10 -s ${ }^{14} \mathrm{C}$ estimates in the carbon atoms of Glc 6-P shown in Table 1, to quantitatively predict the ${ }^{14} \mathrm{C}$ labelling of various carbon atoms of the octulose phosphates formed by Eqs. (3) and (6).

Octulose was isolated as the bisphosphate which is assumed to have the same labelling pattern as D- $g$-D- $i$ oct 8-P (see Results and discussion and the reaction scheme). D- $g$-D- $i$-oct $1,8-\mathrm{P}_{2}$ was degraded by Ald cleavage to DHAP and Ara 5-P followed by selective chemical oxidation of the 3- and 5-carbon fragments (see Methods section). The predicted degree of positional carbon isotopic labelling in $\mathrm{D}-g$ - $\mathrm{D}-i$-oct $1,8-\mathrm{P}_{2}$ is calculated as follows. Reaction of Fru 6-P and Glc 6-P (Eq. (1)) will cause positions 1, 2 and 3 of Oct 8-P to contain hexose 6-P carbons 1, 2 and 1, respectively. By summing the activities of carbons 1, 2 and 1 of Glc 6-P and expressing the sum as $100 \%$, one can calculate the relative activity of the top three carbons of octulose $(3.2+3.2+3.2=9.6)$ then $(3.2 / 9.6) 100=33.3 \%$ as shown in the bracketed values in the 10-s 'Predicted' column of Table 1 . Similarly the bottom 5 carbon atoms of D- $g$-D- $i$-oct $1,8-\mathrm{P}_{2}$ have relative radioactivities identical to carbons $2-6$ of Glc 6-P $(3.2,37.2,50.5,2.5$ and 3.4, respectively). When their sum (96.8) is expressed as 100 , the relative activity for C-4 of octulose is (3.2/ $96.8) 100=3.3 \%$, for C-5 + C-6 + C-7 $\quad((37.2+50.5$
$+2.5) / 96.8) 100=93.2 \%$ and for C-8, (3.4/96.8)100 $=3.5 \%$. All of the predicted values for octulose-P data in Tables 1 and 2 are calculated in the above manner.

\section{References}

Anderson JM, Boardman NK (1966) Fractionation of the photochemical systems of photosynthesis. I. Chlorophyll contents and photochemical activities of particles isolated from spinach chloroplasts. Biochem Biophys Acta 112:403-421

Andrews P, Hough L, Picken JM (1965) The biosynthesis of polysaccharides. Incorporation of D- $\left[1-{ }^{14} \mathrm{C}\right]$ glucose and D$\left[6-{ }^{14} \mathrm{C}\right]$ glucose into plum leaf polysaccharides. Biochem $\mathrm{J}$ 94:75-80

Arnon DI (1949) Copper enzymes in isolated chloroplasts. Polyphenol oxidase in Beta vulgaris. Plant Physiol 24:1-15

Arora KK (1984) Studies on carbohydrate metabolism in cancer. $\mathrm{Ph} \mathrm{D}$ thesis. Australian National University, Canberra, Australia

Arora KK, Cortis P, Bleakley PA, Williams JF (1985) Identification and measurement of D-glycero-D-ido octulose 1, 8-bisphosphate: D-altro-heptulose 7-phosphotransferase enzyme in tissues with L-type pentose phosphate pathway activity. Int J Biochem 17:1329-1337

Arora KK, MacLeod JK, Williams JF (1987) High yield synthesis of ${ }^{14} \mathrm{C}$ labelled intermediates of the L-type pentose pathway: octulose mono and bisphosphates, sedoheptulose 1,7- bisphosphate and D-arabinose 5-phosphate. J Label Compd Radiopharmaceut 24:205-218

Bandurski RS, Axelrod B (1951) The chromatographic identification of some biologically important phosphate esters. J Biol Chem 193:405-410

Bartlett MRE, Collins JG, Flanigan IL, MacLeod JK, Williams JF (1989) $\mathrm{CO}_{2}$ labelling of octulose bisphosphates during photosynthesis. An NMR study using intact spinach leaves. Biochem Int 18:35-46

Beck E, Hopf H (1982) Carbohydrate metabolism. Prog Bot 44:132-153

Begbie R, Richtmyer NK (1966) The isolation of some heptoses, heptuloses, octuloses and nonuloses from Primula officinalis. J Carbohydr Res 2:272-288

Benson AA, Kawauchi S, Hays P, Calvin M (1952) The path of carbon in photosynthesis XVI Kinetic relationships of the intermediates in steady state photosynthesis. J Am Chem Soc 74:4474-4482

Bergmeyer HU, Bernt E (1974) Fructose-1,6-diphosphate aldolase; UV assay, Manuel method. In: Bergmeyer HU (ed) Methods of enzymatic analysis, vol 2. Academic Press, New York, pp 1100-1105

Bleakley PA, Arora KK, Williams JF (1984) Evidence that aldolase and arabinose 5-phosphate are components of pentose pathway reactions in liver in vitro. Biochem Int $8: 491-500$

Brand K (1974) Transaldolase. In: Bergmeyer HU (ed) Methods of enzymatic analysis, vol 2. Academic Press, New York, pp 710-714

Brin K (1974) Transketolase. In: Bergmeyer HU (ed) Methods of enzymatic analysis, vol 2. Academic Press, New York, pp 703-709

Charlson AJ, Richtmyer NK (1959) Isolation of D-glycero-Dmanno-octulose from the avocado. J Am Chem Soc $81: 1512-1513$ 
Calvin M (1956) The photosynthetic carbon reduction cycle. J Chem Soc (London):1895-1915

Clark MG, Williams JF, Blackmore PF (1974) Exchange reactions in metabolism. Catal Rev 9:35-77

Cluley HJ (1962) Suspension scintillation counting of carbon-14 barium carbonate. The Analyst 81:170-177

Daley LS, Bidwell RGS (1977) Phosphoserine and phosphohydroxypyruvic acid. Evidence for their role as early intermediates in photosynthesis. Plant Physiol 60:109-114

Flanagan IL, Collins JG, Arora KK, MacLeod JK, Williams JF (1993) Exchange reactions catalyzed by group-transferring enzymes oppose the quantitation and unravelling of the identity of the pentose pathway. Eur J Biochem 213: 477-485

Furbank RT, Lilley RMcC (1981) Reductive pentose phosphate cycle and oxidative carbohydrate metabolic activities in pea chloroplast stroma extracts. Plant Physiol 67:1036-1041

Genovese J, Schmidt K, Katz J (1970) Enzymic degradation of isotopically labeled compounds I. Degradation of ${ }^{14} \mathrm{C}$ labelled glycerol. Anal Biochem 34:161-169

Gibbs M, Horecker BL (1954) The mechanism of pentose phosphate conversion to hexose monophosphate II. With pea leaf and pea root preparations. J Biol Chem 208:813820

Hatch MD, Slack CR (1966) Photosynthesis by sugar cane leaves. A new carboxylation reaction and the pathway of sugar formation. Biochem J 101:103-111

Heath RL (1984) A new type of hexose monophosphate shunt in Chlorella sorokiniana. Plant Physiol 75:964-967

Heldt HW (1980) Measurement of metabolite movement across the envelope and of the $\mathrm{pH}$ in the stroma and the thylakoid space in intact chloroplasts. In: Pierro S (ed) Methods in enzymology, vol 69C. Academic Press, New York, pp 604-613

Heldt HW, Chong CJ, Lorimer GH (1978) Phosphate requirement for the light activation of ribulose 1,5 bisphosphate carboxylase in intact spinach chloroplasts. FEBS Lett 92:234-240

Heldt HW, Portis AR, Lilly RMcC, Mosbach A, Chon CJ (1980) Assay of nucleotides and other phosphate-containing compounds in isolated chloroplasts by ion-exchange chromatography. Anal Biochem 101:278-287

Horecker BL (2002) The pentose phosphate pathway. J Biol Chem 277:47965-47971

Horecker BL, Gibbs M, Klenow H, Smyrniotis PZ (1954) The mechanism of pentose phosphate conversion to hexose monophosphate I. With liver enzyme preparation. J Biol Chem 207:393-403

Howarth OW, Pozzi N, Vlahov G, Bartels D (1996) NMR structural analysis of a tri-O-isopropylidene derivative of Dglycero-D-ido-octulose, the major sugar found in resurrection plant Craterostigma plantagineum. Carbohydr Res 289:137-142

Jensen RG, Bassham JA (1966) Photosynthesis by isolated chloroplasts. Proc Natl Acad Sci 56:1095-1101

Kaiser WM, Bassham JA (1979) Carbon metabolism of chloroplasts in the dark: oxidative pentose cycle versus glycolytic pathway. Planta 144:193-200

Kandler O, Gibbs M (1956) Asymmetric distribution of $\mathrm{C}^{14}$ in the glucose phosphates formed during photosynthesis. Plant Physiol 31:411-412

Kapuscinski MK, Franke FP, Flanigan IL, MacLeod JK, Williams JF (1985) Improved methods for the enzymic preparation and chromatography of octulose phosphates. Carbohydr Res 140:69-79
Karadsheh NS, Tejwani GA, Ramaiah A (1973) Sedoheptulose7-phosphate kinase activity of phosphofructokinase from different tissues of rabbit. Biochim Biophys Acta 327:66-81

Kelly GJ, Latzko E (1977) Chloroplast phosphofructokinase. I. Proof of phosphofructokinase activity in chloroplasts. Plant Physiol 60:290-294

Latzko E, Gibbs M (1969) Enzyme activities of the carbon reduction cycle in some photosynthetic organisms. Plant Physiol 44:295-300

Latzko E, Gibbs M (1974) Alkaline $C_{1}$-fructose-1,6-diphosphatase. In: Bergmeyer HU (ed) Methods of enzymatic analysis, vol 2. Academic Press, New York, pp 881-884

Lilley RMcC, Walker DA (1979) Studies with the reconstituted chloroplast system. In: Gibbs M, Latzko E (eds) Encyclopedia of plant physiology new series, vol 6. Springer Verlag, Berlin, pp 41-53

Lilley RMcC, Fitzgerald MP, Rienits KG, Walker DA (1975) Criteria of intactness and the photosynthetic activity of spinach chloroplast preparations. New Phytol 75:1-10

MacLeod JK, Flanigan IL, Williams JF, Collins JG (2001) Mass spectrometric studies of the path of carbon in photosynthesis: positional isotopic analysis of ${ }^{13} \mathrm{C}$-labelled $\mathrm{C}_{4}$ to $\mathrm{C}_{7}$ sugar phosphates. J Mass Spectrom 36:500-508

Murphy DJ, Walker DA (1982) The properties of transketolase from photosynthetic tissue. Planta 155:316-320

Pettersson G, Ryde-Pettersson U (1988) A mathematical model of the Calvin photosynthesis cycle. Eur J Biochem 175:661-672

Portis AR, Chon CJ, Mosbach A, Heldt HW (1977) Fructose and sedoheptulosebisphosphatase. The sites of a possible control of $\mathrm{CO}_{2}$ fixation by light-dependent changes in stromal $\mathrm{Mg}^{2+}$ concentration. Biochim Biophys Acta 461:313-325

Robinson SP (1983) Isolation of intact chloroplasts with high $\mathrm{CO}_{2}$ fixation capacity from sugarbeet leaves containing calcium oxalate. Photosynth Res 4:281-287

Robinson SP, Walker DA (1981) The photosynthetic carbon reduction cycle. In: Hatch MD, Boardman NK (eds) The biochemistry of plants: a comprehensive treatise, vol. 8 . Academic Press, New York, pp 194-236

Rosenberg H (1959) The detection of phosphates on chromatograms. J Chromatogr 2:487-489

Schafer G, Heber U, Heldt HW (1977) Glucose transport into spinach chloroplasts. Plant Physiol 60:286-289

Stiller M (1962) The path of carbon in photosynthesis. Annu Rev Plant Physiol 13:151-170

Stitt M, Wirtz W, Heldt HW (1980) Metabolite levels during induction in the chloroplast and extrachloroplast compartments of spinach protoplasts. Biochim Biophys Acta 593:85-102

Tashima Y, Yoshimura N (1975) Control of rabbit liver fructose1,6-diphosphatase activity by magnesium ions. J Biochem (Tokyo) 78:1161-1169

Van Sumere CF, Shu P (1957) Mechanism of biosynthesis of mycelial glucosan from pentoses by Aspergillus niger. Can J Biochem Physiol 35:445-448

Vernon LP (1960) Spectrophotometric determination of chlorophylls and pheophytins in plant extracts. Anal Biochem 32 :1144-1150

Volk WA (1960) Purification and properties of phospharabinoseisomerase from Propionibacterium pentosaceum. J Biol Chem 235:1550-1553

Walker DA, Lilley RMcC (1974) Autocatalysis in a reconstructed chloroplast system. Plant Physiol 54:950-952

Williams JF (1980) A critical examination of the evidence for the reactions of the pentose pathway in animal tissues. Trends Biochem Sci 5:315-320 
Williams JF (2004) Pentose phosphate pathway, History of. In: Lennarz WJ, Lane M Daniel (eds) Encyclopedia of biological chemistry, vol 3. Elsevier Inc, Oxford, pp 216-225

Williams JF, Clark MG (1971) An error in metabolism: the pentose phosphate cycle. Search 2:80-88

Williams JF, Rienits KG, Schofield PJ, Clark MG (1971) The pentose phosphate pathway in rabbit liver. Studies on the metabolic sequence and quantitative role of the pentose phosphate cycle by using a system in situ. Biochem $\mathrm{J}$ 123:923-943

Williams JF, Blackmore PF, Clark MG (1978a) New reaction sequences for the non-oxidative pentose phosphate pathway. Biochem J 176:257-282

Williams JF, Clark MG, Blackmore PF (1978b) The fate of ${ }^{14} \mathrm{C}$ in glucose 6-phosphate synthesised from $\left[1-{ }^{14} \mathrm{C}\right]$ ribose 5-phosphate by enzymes of rat liver. Biochem J 176:241-256

Williams JF, Clark MG, Arora KK, Reichstein IC (1984) Glucose 6-phosphate formation by L-type pentose pathway reactions of rat liver in vitro: further evidence. Hoppe Seyler's Z Physiol Chem 365:1425-1434

Williams JF, Clark MG, Arora KK (1985) ${ }^{14} \mathrm{C}$ labelling of octulose bisphosphates by L-type pentose pathway reactions in liver in situ and in vitro. Biochem Int 11:97-106

Williams JF, Arora KK, Longnecker JP (1987) The pentose pathway: a random harvest. Impediments which oppose acceptance of the classical (F-type) pentose cycle for liver, some neoplasms and photosynthetic tissue The case for the L-type pentose pathway. Int J Biochem 19:749-817

Wood T (1968) The detection and identification of intermediates of the pentose phosphate cycle and related compounds. J Chromatogr 35:352-361

Woodrow IE, Walker DA (1982) Activation of wheat chloroplast sedoheptulose bisphosphatase: a continuous spectrophotometric assay. Arch Biochem Biophys 216:416-422 